Document downloaded from:

http://hdl.handle.net/10251/64812

This paper must be cited as:

Català, S.; Campo, ED.; Barreno, E.; García-Breijo, F.; Reig Armiñana, J.; Casano, L. (2016). Coordinated ultrastructural and phylogenomic analyses shed light on the hidden phycobiont diversity of Trebouxia microalgae in Ramalina fraxinea. Molecular Phylogenetics and Evolution. 94:765-777. doi:10.1016/j.ympev.2015.10.021.

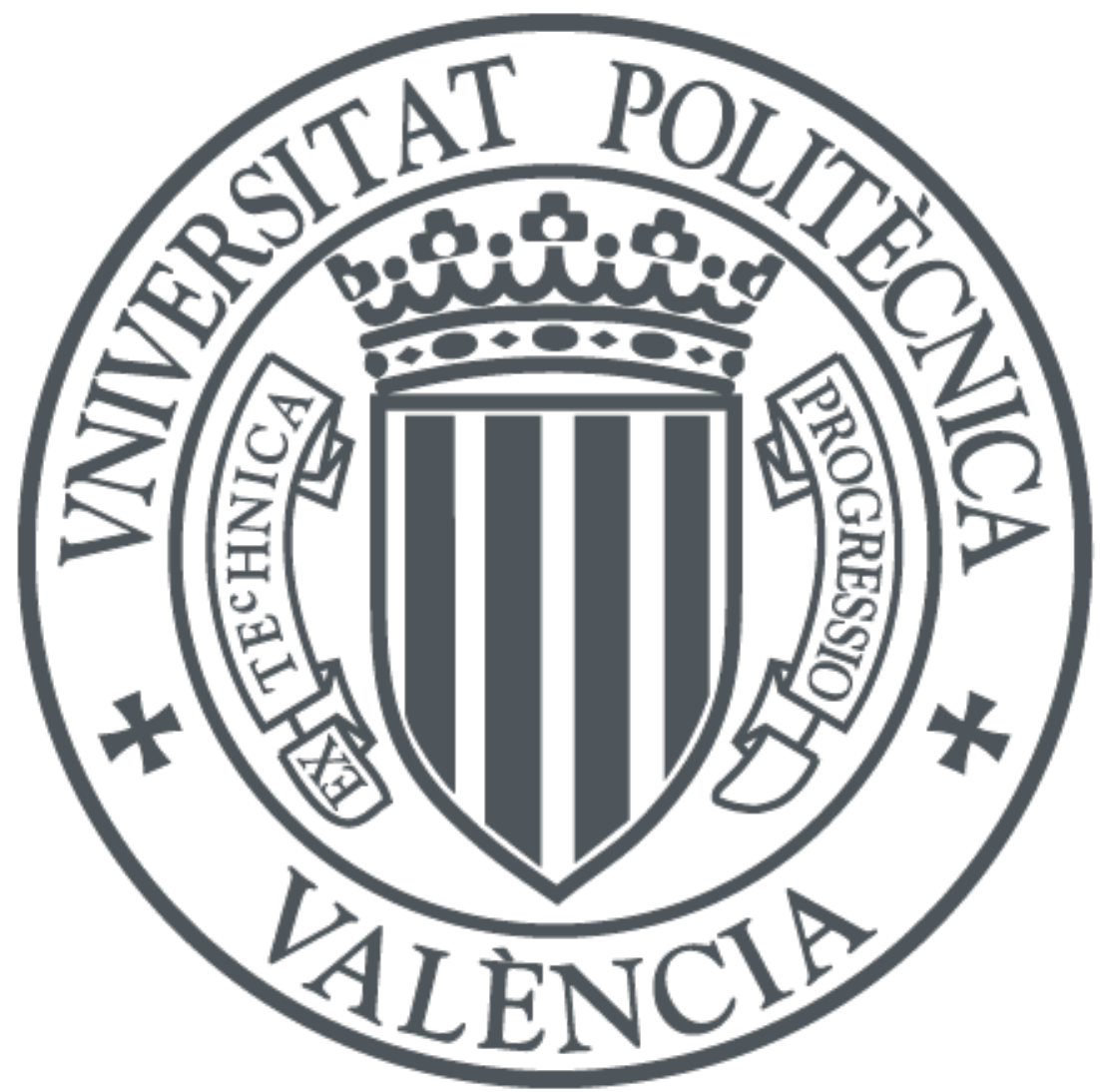

The final publication is available at

https://dx.doi.org/10.1016/j.ympev.2015.10.021

Copyright Elsevier

Additional Information 


\title{
Coordinated ultrastructural and phylogenomic analyses shed light on the hidden phycobiont diversity of Trebouxia microalgae in Ramalina fraxinea
}

\author{
Santiago Cataláa,d, Eva M. del Campo ${ }^{\mathrm{b}, *}$, Eva Barreno ${ }^{\mathrm{a}}$, Francisco J. García-Breijo ${ }^{\mathrm{c}}$, José Reig-Armiñana ${ }^{\mathrm{a}}$, \\ Leonardo M. Casano ${ }^{\text {b }}$ \\ ${ }^{a}$ Dpto. Botánica, Jardí Botànic, ICBIBE, Fac. C. Biológicas, C/ Dr. Moliner 50, 46100 Burjassot, Valencia, Spain \\ ${ }^{\mathrm{b}}$ Dpto. Ciencias de la Vida, Universidad de Alcalá, 28805 Alcalá de Henares, Madrid, Spain \\ ${ }^{\mathrm{c}}$ Dpto. Ecosistemas Agroforestales, Universidad Politécnica de Valencia, Camino de Vera s/n, 46022 Valencia, Spain \\ ${ }^{\mathrm{d}}$ Instituto Agroforestal Mediterráneo, Universidad Politécnica de Valencia, Camino de Vera s/n, 46022 Valencia, Spain ${ }^{1}$
}

Keywords:

Coexistence

Cryptic species

Lichen

Ramalina

Symbiosis

Trebouxia

\begin{abstract}
A B S T R A C T
The precise boundary delineations between taxa in symbiotic associations are very important for evolutionary and ecophysiological studies. Growing evidence indicates that in many cases, the use of either morphological characters or molecular markers results in diversity underestimation. In lichen symbioses, Trebouxia is the most common genus of lichen phycobionts, however, the diversity within this genus has been poorly studied and as such there is no clear species concept. This study constitutes a multifaceted approach incorporating aspects of ultrastructural characterization by TEM and phylogenomics to evaluate the morphological and genetic diversity of phycobionts within the sexually reproducing lichen Ramalina fraxinea in the context of Mediterranean and temperate populations. Results reveal an association with at least seven different Trebouxia lineages belonging to at least two species, T. decolorans and T. jamesii, and diverse combinations of such lineages coexisting within the same thallus depending on the analyzed sample. Some of these lineages are shared by several other non-related lichen taxa. Our findings indicate the existence of a highly diverse assemblage of Trebouxia algae associating with $R$. fraxinea and suggest a possible incipient speciation within $T$. decolorans rendering a number of lineages or even actual species. This study stresses the importance of coordinated ultrastructural and molecular analyses to improve estimates of diversity and reveal the coexistence of more than one Trebouxia species within the same thallus. It is also necessary to have clearer species delimitation criteria within the genus Trebouxia and microalgae in general.
\end{abstract}

\section{Introduction}

The term "symbiosis" was originally coined by de Bary in 1879 in his monograph "Die Erscheinung der Symbiose", which described close and long-term physical associations between different organisms. Symbioses include different levels of mutualism encompassing interactions ranging from those in which both the host and the symbiont benefit from the interaction, to antagonistic interactions where the symbiont benefits, and the host suffers damage (Wilkinson, 2001). Lichens are classic symbiotic associations resulting in complex systems with a specific biological organization

E-mail address: eva.campo@uah.es (E.M. del Campo).

1 Actual address.
(Chapman and Margulis, 1998). Such associations involve at least two very different organisms, a heterotrophic fungus (mycobiont) and a photobiont [cyanobacteria (cyanobiont) or unicellular green algae (phycobiont)]. The spatial genetic structure of lichen symbionts is influenced by both ecological and evolutionary factors. These factors include the mode of photobiont transmission, geographical distance and adaptation to local environmental conditions. Phycobionts can be transmitted either vertically (codependency) or horizontally (independency). Vertical transmission involves phycobiont dispersal as part of the vegetative propagule and is believed to be the predominant process in exclusively, or almost exclusively, asexual lichen species (Cassie and PierceyNormore, 2008). Alternatively, horizontal transmission involves the incorporation of new phycobionts within a germinating spore or vegetative structure (Werth and Sork, 2010). Concordant patterns in the genetic structure of symbionts are expected in 
vertically transmitted symbioses. However, such patterns are rarely observed in lichen symbioses [e.g. Lobaria pulmonaria (Werth and Scheidegger, 2012)]. Conversely, markedly different genetic structures of photobionts and mycobionts are more often observed, even in vertically transmitted lichen species (Leavitt et al., 2015; Otálora et al., 2010; Piercey-Normore, 2006; Werth and Sork, 2010; Wornik and Grube, 2010; Yahr et al., 2006). Changes in a symbiotic organism's reproductive mode may be governed by trade-offs in the fitness of the symbiosis, as proposed by Buschbom and Mueller (2006). In lichen species with both asexual and sexual modes of propagation, the asexual propagation system preponderates when the relationships between symbionts is optimal in a given environment [e.g. Lobaria pulmonaria (Dal Grande et al., 2012)]. Conversely, when the established symbiosis becomes suboptimal, decreasing global fitness due to changes in the environment, sexual reproduction may be preferred, providing access to new partners. Under the assumption of high flexibility in the specificity and ecological selection of the phycobionts, the ability to establish new fungus-phycobiont associations has enabled lichens to colonize varied and wide-ranging habitats (Doering and Piercey-Normore, 2009). Several studies have demonstrated that lichen mycobionts associate with different phycobionts under different environmental conditions, or in different geographical regions (Blaha et al., 2006; Casano et al., 2011; Cordeiro et al., 2005; del Campo et al., 2013; Muggia et al., 2008, 2010; Peksa and Škaloud, 2011; Schmull et al., 2011; Fedrowitz et al., 2012; Rikkinen, 2013).

In lichens, most interactions between the photobionts and the outside world are mediated by the mycobiont mitigating many adverse environmental conditions. As environmental changes rarely affect all lichens within a local community in the same way and with the same intensity, a wide range of compatible mycobionts can increase photobiont resistance against many detrimental factors (Rikkinen, 2003). Reciprocally, a wide spectrum of compatible photobionts can increase mycobiont stress tolerance. In some cases the coexistence of phycobionts with complementary physiological performances within the same thallus can increase resistance against adverse environmental conditions (Casano et al., 2011). Additionally, lichen behavior seems to be modulated by the predominant phycobiont (Álvarez et al., 2015). Since the success of the lichen seems to depend to some extent on photobionts, knowledge about the photobiont composition of lichens will enhance our understanding of how some lichens can evolve tolerance to certain environmental stresses. In addition, observations in Ramalina farinacea support a model where ecological diversification and speciation of lichen symbionts in different habitats could include a transient phase consisting of associations with more than one photobiont in individual thalli (del Campo et al., 2013). Such diversification is likely to be promoted by different physiological backgrounds.

In previous studies we investigated the lichen species Ramalina farinacea as a model of lichen symbiosis in which a fungal species specifically associates with two different Trebouxia phycobionts (provisionally named TR1 and TR9) coexisting within each lichen thallus (del Campo et al., 2010d; Casano et al., 2011). In this lichen species, the codispersal of symbionts within vegetative propagules may be partially responsible of the strict preservation of this pattern of algal coexistence. The main goal of this study is to investigate the phycobiont and the possible coexistence of more than one Trebouxia taxa in Ramalina fraxinea, which mainly disperses via fungal ascospores which need to find compatible photobionts to relichenize.

Here we present the results of an in-depth morphological and molecular study of the intrathalline phycobiont diversity of the fruticose lichen Ramalina fraxinea. Fruticose species have a growth pattern that facilitates the separation of true individuals for further morphological and molecular analyses. TEM observations and molecular tools were used to investigate nine populations obtained from different locations within the Iberian Peninsula, characterized by diverse environmental conditions within the context of Mediterranean and temperate climates. These studies provided evidence that there are at least seven different lineages of the genus Trebouxia in the analyzed populations. Six of them are similar to T. decolorans s.a., while the other one seems to be T. jamesii. These lineages differ in their morphologies and genotypes and coexisted in different number and combinations within the studied thalli. Five of the seven Trebouxia lineages identified in Ramalina fraxinea were previously detected in other non related lichens, while two lineages seem to symbiotize only with Ramalina fraxinea.

\section{Materials and methods}

\subsection{Taxon sampling}

For this study, all the analyzed Ramalina fraxinea thalli were collected from nine populations within the Iberian Peninsula (Table 1) in four geographic areas (A-C in Figs. 3 and 5). The areas are characterized by different ecological conditions and thalli were collected on different phorophytes (Table 1). Sampling areas were located in natural habitats, or abandoned farmlands, at different altitudes. All of the studied materials were deposited in the Lichen Symbiogenesis Laboratory of the Department of Botany, Universitat de València (Valencia, Spain), and stored at a temperature of $-20^{\circ} \mathrm{C}$

\subsection{Morphological analysis of 'in thallus' lichen phycobionts}

Phycobionts inside thallus were examined in pieces of rehydrated $R$. fraxinea thalli from different areas (Table 1 ) by light

Table 1

Areas in which samples of Ramalina fraxinea were collected.

\begin{tabular}{|c|c|c|c|}
\hline Site & $\begin{array}{l}\text { Area/geographic coordinates/ } \\
\text { altitude/collection data }\end{array}$ & Phorophyte & Specimens \\
\hline A & $\begin{array}{l}\text { Tarna (Caso, Asturias) } / 43^{\circ} 06^{\prime} 51.89^{\prime \prime} \mathrm{N} \\
5^{\circ} 13^{\prime} 19.14^{\prime \prime} \mathrm{W} / 1219 \mathrm{~m} /(\text { leg. S. Català, A. } \\
\text { Avellanosa, R. Barbero and H. de Dios, 22- } \\
05-2010)\end{array}$ & $\begin{array}{l}\text { Quercus } \\
\text { faginea }\end{array}$ & AA1-6 \\
\hline A & $\begin{array}{l}\text { Saliencia (Somiedo, Asturias)/ } \\
43^{\circ} 06^{\prime} 24.18^{\prime \prime} \mathrm{N} 6^{\circ} 10^{\prime} 00.27^{\prime \prime} \mathrm{W} / 1423 \mathrm{~m} / \\
\text { (leg. S. Català, A. Avellanosa, R. Barbero } \\
\text { and H. de Dios, 23-05-2010) }\end{array}$ & $\begin{array}{l}\text { Quercus } \\
\text { petraea }\end{array}$ & AB1-6 \\
\hline A & $\begin{array}{l}\text { Pola de Somiedo (Somiedo, Asturias)/ } \\
43^{\circ} 05^{\prime} 42.27^{\prime \prime} \mathrm{N} 6^{\circ} 15^{\prime} 07.72^{\prime \prime} \mathrm{W} / 826 \mathrm{~m} / \\
\text { (leg. S. Català, A. Avellanosa, R. Barbero } \\
\text { and H. de Dios, 23-05-2010) }\end{array}$ & $\begin{array}{l}\text { Fraxinus } \\
\text { excelsior }\end{array}$ & AC1-6 \\
\hline B & $\begin{array}{l}\text { Sierra Cebollera (La Rioja) } / 42^{\circ} 02^{\prime} 19.28^{\prime \prime} \mathrm{N} \\
2^{\circ} 42^{\prime} 34.84^{\prime \prime} \mathrm{W} / 1680 \mathrm{~m} /(\text { leg. F. Gasulla, } \\
03-04-2010 \text { ) }\end{array}$ & $\begin{array}{l}\text { Quercus } \\
\text { pyrenaica }\end{array}$ & $\mathrm{R} 1-6$ \\
\hline B & $\begin{array}{l}\text { Otxagavía (Navarra) } / 42^{\circ} 54^{\prime} 28.56^{\prime \prime} \mathrm{N} \\
1^{\circ} 05^{\prime} 15.81^{\prime \prime} \mathrm{W} / 794 \mathrm{~m} /(\text { leg. E. Verdú and } \\
\text { S. Català, } 16-03-2010)\end{array}$ & $\begin{array}{l}\text { Fraxinus } \\
\text { excelsior }\end{array}$ & N1-6 \\
\hline C & $\begin{array}{l}\text { El Escorial (Madrid)/40.34'48.91"N, } \\
4^{\circ} 09^{\prime} 02.94^{\prime \prime} \mathrm{W} / 966 \mathrm{~m} /(\text { leg. F. Gasulla, } 15- \\
03-2010)\end{array}$ & $\begin{array}{l}\text { Quercus } \\
\text { pyrenaica }\end{array}$ & M1-6 \\
\hline C & $\begin{array}{l}\text { Villaviciosa de Odón } / 40^{\circ} 22^{\prime} 33.34^{\prime \prime} \mathrm{N} \\
3^{\circ} 55^{\prime} 23.51^{\prime \prime} \mathrm{W} / 650 \mathrm{~m} /(\text { leg. J.C. Zamora) }\end{array}$ & $\begin{array}{l}\text { Olea } \\
\text { europaea/ } \\
\text { Prunus dulcis }\end{array}$ & $\begin{array}{l}\text { V01-3/ } \\
\text { VP1-3 }\end{array}$ \\
\hline $\mathrm{D}$ & $\begin{array}{l}\text { Bronchales (Teruel) } / 40^{\circ} 30^{\prime} 09.75^{\prime \prime} \mathrm{N} \\
1^{\circ} 36^{\prime} 16.95^{\prime \prime} \mathrm{W} / 1687 \mathrm{~m} /(\text { leg. S. Català, } 13- \\
05-2010)\end{array}$ & $\begin{array}{l}\text { Quercus } \\
\text { pyrenaica }\end{array}$ & T1-6 \\
\hline D & $\begin{array}{l}\text { Sierra de Javalambre (Teruel)/ } \\
40^{\circ} 10^{\prime} 02.19^{\prime \prime} \mathrm{N} 1^{\circ} 01^{\prime} 08.76^{\prime \prime} \mathrm{W} / 1529 \mathrm{~m} / \\
\text { (leg. S. Català and E. Verdú, 03-04-2010) }\end{array}$ & $\begin{array}{l}\text { Robinia } \\
\text { pseudoacacia }\end{array}$ & J1-6 \\
\hline
\end{tabular}


microscopy and TEM. The specimens were fixed in 2\% Karnovsky fixative for $2 \mathrm{~h}$ at $4{ }^{\circ} \mathrm{C}$ and were then washed three times with $0.01 \mathrm{M} \mathrm{PBS}, \mathrm{pH} 7.4$, for $15 \mathrm{~min}$ each and fixed with $2 \% \mathrm{OsO}_{4}$ in $0.01 \mathrm{M}$ PBS, $\mathrm{pH} 7.4$, for $2 \mathrm{~h}$ at $4{ }^{\circ} \mathrm{C}$. Thereafter, they were washed in $0.01 \mathrm{M}$ PBS, pH 7.4 , for 15 min and then dehydrated at room temperature in a graded series of ethanol, starting at $50 \%$ and increasing to $70 \%, 95 \%$ and $100 \%$ for no less than $20-30$ min at each step. The fixed and dehydrated samples were embedded in Spurr's resin according to the manufacturer's instructions (http://www. emsdiasum.com/microscopy/technical/datasheet/14300.aspx). For light microscopy (LM) analyses, 1-2 mm sections were cut from samples of $R$. fraxinea thalli embedded in Spurr's resin using a diamond knife (DIATOME Histo $45^{\circ}$ ) and an ultramicrotome (Ultratome Nova LKB Bromma). The sections were stained with $1 \%$ toluidine blue and observed with an Olympus Provis AX 70 microscope equipped with an Infinity 2-3C Lumenera ${ }^{\circledR}$ digital camera and "Infinity Analyze" Software v.6.4.1. For TEM, $90 \mathrm{~nm}$ sections were cut with a diamond knife (DIATOME Ultra $45^{\circ}$ ) using an ultramicrotome (Ultratome Nova LKB Bromma), mounted on copper grids of 100 mesh, and post-stained with $2 \%(\mathrm{w} / \mathrm{v})$ aqueous uranyl acetate and $2 \%$ lead citrate. The prepared sections were observed with a JEOL JEM-1010 (80 kV) electron microscope, equipped with a MegaView III digital camera and 'AnalySIS' image acquisition software, at the SCSIE service of the University of Valencia. To obtain the values shown in Table 2, at least 50 and up to 100 measurements of each structure and organelle analyzed in different samples were performed. Measurements were carried out using the computer program Adobe Photoshop CS6, which had been correctly calibrated.

\subsection{DNA isolation, amplification, and sequencing}

All thalli were surface washed by immersion for $10 \mathrm{~min}$ in aqueous sodium hypochlorite (final concentration $3 \% \mathrm{w} / \mathrm{v}$ ) and then with sterile distilled water prior to DNA isolation. Total DNA was isolated from each collected lichen thallus with the DNAeasy Plant Mini Kit (Qiagen GmbH, Hiden, Germany). Algal nrITS were amplified using the algal-specific primers nr-SSU1780 (Piercey-Normore and DePriest, 2001) and the universal primer ITS4 (White et al., 1990). A portion of the chloroplast psbA gene encoding for the D1 protein was amplified using the primer pair psbAchl1/psbAchl2 (del Campo et al., 2010a). A portion of the chloroplast 23SrDNA encoding for the 23S rRNA was amplified using the primer pair 23SU1/23SU2 (del Campo et al., 2010c). An additional amplification product from the 23SrDNA including a portion the IB4 intron cL2263 (Casano et al., 2011) was obtained from some thalli using the primer pair 23S-Tj1/23S-Tj2 (23S-Tj1: 5'-TGA ATC AGG ACG CTT GAC AG-3'/23S-Tj2: 5'-CTT TGC ACA TCT CCG TTA CC- $\left.3^{\prime}\right)$. Fungal nrITS were amplified using the primers ITS1F (Gardes and Bruns, 1993) and ITS4 (White et al., 1990). A portion of the fungal gene encoding $\beta$-tubulin was amplified with the primer pair Bt3LM/Bt10LM (Myllys et al., 2001). Amplification reactions were carried out by PCR in a total reaction volume of $25 \mu \mathrm{L}$ and using Illustra Hot Start Mix RTG (GE Healthcare, NJ). Negative controls, without a DNA template, were included in every round of PCR amplifications to eliminate false-positive results caused by contaminants in the reagents. Cycling conditions were as follows: one cycle at $95{ }^{\circ} \mathrm{C}$ for $2 \mathrm{~min}$ and 40 cycles at $95{ }^{\circ} \mathrm{C}$ for $30 \mathrm{~s}, 55^{\circ} \mathrm{C}$ for $30 \mathrm{~s}$ and $72{ }^{\circ} \mathrm{C}$ for $2 \mathrm{~min}$ and a final extension at $72{ }^{\circ} \mathrm{C}$ for $7 \mathrm{~min}$. Amplification products were subjected to electrophoresis through $1.5 \%$ agarose gels. The corresponding bands were excised from the gel, purified with a DNA gel extraction kit (Qiaex II; Qiagen GmbH, Hiden, Germany) and directly used for sequence analysis. Purified amplicons were sequenced using the Big DyeTM Terminator Cycle Sequence Ready Reaction Kit II (Applied Biosystems Co. Foster City, CA), separated by automated multicapillary electrophoresis, and further analyzed on an ABI Prism 3730 Genetic Analyzer (Applied Biosystems Co.).

\subsection{Alignments, phylogenetic analyses, database searches, and genetic differentiation estimates}

All the sequences determined in this study were aligned using the default parameters implemented in Muscle 3.6 (Edgar, 2004), by using Geneious R6, Biomatters Inc. Data sets were subjected to maximum-likelihood (ML) with PhyML (Guindon et al., 2010) and examined with a Bayesian approach by using BEAST (Drummond et al., 2012). Trees were displayed with FIGTREE v1.3 (Rambaut, 2008). For Bayesian analyses, the Markov chain Monte Carlo method from a random starting tree was initiated in the Bayesian inference and run for $10^{7}$ generations. Sampling was every 100th generation. After chain convergence analysis, all samples obtained during the first 50,000 generations were discarded as burnin. Posterior probabilities for each node were inferred from the resulting consensus tree. Bootstrap probabilities (Felsenstein, 1985) were calculated to estimate the robustness of the clades from 1000 replicates of the data. Statistical parsimony networks were reconstructed using TCS 1.18 (Clement et al., 2000). Database searches were performed by using BLAST (Altschul et al., 1997). Genetic maps were constructed with Geneious R6, Biomatters Inc.

\section{Results}

\subsection{Diversity of Ramalina fraxinea phycobionts based on morphological analyses by TEM}

Morphological characterization of $R$. fraxinea was performed based on structural features of the thallus and the ultrastructure of phycobionts by LM and TEM, respectively. As shown in Fig. 1, $R$. fraxinea thalli have a cortex with a thin outer cortex and rich chondroid tissue. A thin axial cordon can be seen in the center of the thallus. Numerous bacterial colonies and cyanobacteria clusters can be observed associated with the outer cortex. The phycobiont layer appears below the chondroid tissue with numerous hyphae and algae. Morphological analyses of phycobionts using TEM based on the ultrastructure of plastids and pyrenoids allowed distinguishing of at least six different phycobionts (Fig. 2) whose general features are summarized in Table 2. Cells of morphotype A (Fig. 2A) have a large single pyrenoid (gelatinosa/irregularis type) (Friedl, 1989) within a single lobated chloroplast in which the arrangement of thylakoid membranes is loose. Their disposition is untidy, with $2-3$ membranes in the stackings. This cell type has numerous small peripheral electron-dense vesicles. The presence of mitochondria is scarce. The secretion space is narrow. Starch was present as small grains, which are blackish and scarce. Cells of morphotype B (Fig. 2B) have a similar size when compared with those of morphotype A. However, cells of this morphotype have no pyrenoids or starch, having a single lobated chloroplast. The distribution of thylakoid membranes is loose, their arrangement is untidy, and the membranes are in stackings of 2-3. Mitochondria are scarce and smaller than in morphotype A. Peripheral non electron-dense vesicles are numerous and very large. The secretion space is present, but narrow. Cells of morphotype $C$ (Fig. 2C) have a smaller average cell size than those of morphotypes A and B. A single central pyrenoid (irregularis type) (Friedl, 1989) with large pyrenoglobules is present. Starch grains are present, which are white and abundant. There is a single lobate chloroplast in which the disposition of thylakoid membranes is dense, and their arrangement is tidy with stacking of 3-4 membranes. Mitochondria are very scarce. Peripheral vesicles are small and numerous and have a more electron-dense content in the 
periphery than in the center. A secretion space is present. Morphotypes $\mathrm{D}, \mathrm{E}$ and $\mathrm{F}$ are different from that mentioned above, and different from each other with different cell sizes and a thick cell wall of more than $400 \mathrm{~nm}$. Type D (Fig. 2D and Table 2) has a lobated chloroplast with an irregular distribution of thylakoid membranes, dense in some areas and light in others. The arrangement of these membranes is tidy and can form stackings of $>3$. This type has no pyrenoid or starch grains. Mitochondria are large and abundant. Peripheral vesicles are numerous and non electron-dense. A secretion space is present. Morphotype E (Fig. 2E and Table 2) has a lobated chloroplast with a dense distribution of thylakoid membranes and their arrangement is partially tidy. This cell type has a single central pyrenoid with large pyrenoglobules and a dense matrix (gelatinosa/irregularis type) (Friedl, 1989). Mitochondria are scarce and the peripheral vesicles are abundant (only 1 type) and non electron-dense. They contain a blackish starch. A secretion space is present. Type $\mathrm{F}$ (Fig. $2 \mathrm{~F}$ and Table 2 ) has numerous chloroplasts of different sizes with a dense distribution of the thylakoid membranes. The arrangement of these membranes is tidy and can form stackings of $>5$. It has a few mitochondria and numerous vesicles with an electron-dense granular content in a non electrodense matrix. This type has neither pyrenoid nor starch grains.

As shown in Table 2, several samples had at least three different cell types: types A, B and D for M1, types A, C and F for M4 and types A, B and C for M5. These findings suggested the possible coexistence of at least three different morphotypes by thallus in M1, M4 and M5 samples. Other samples showed a lower number of morphotypes, such as AA1 with two morphotypes (B and C) and $\mathrm{T} 1$ with a single morphotype (A).

\subsection{Identity and diversity of Ramalina fraxinea symbionts based on} molecular markers

Algal nrITS (aits) were sequenced from thalli collected from different areas within the Iberian Peninsula growing on different phorophytes (Tables 1 and S1). Blast searching showed that all samples had sequences similar to that of Trebouxia decolorans UTEX B781, except for four (AA1, AA3, VO1 and VO2 in Table S1), which had sequences similar to that of Trebouxia jamesii UTEX 2233. These results suggested that $R$. fraxinea contains at least two distinct Trebouxia species as phycobionts. One of these species was similar to $T$. decolorans UTEX B781 [provisionally named T. decolorans-like phycobionts (TDL phycobionts)], whereas the other species was similar to T. jamesii UTEX 2233 [provisionally named $T$. jamesii-like phycobionts (TJL phycobionts)].

The construction of parsimony networks of algal haplotypes from $R$. fraxinea based on aits sequences with the TCS1.21 program (Clement et al., 2000) showed the existence of 19 haplotypes distributed among at least seven different lineages (L1 to L7 in Fig. 3A). Six of these lineages (L1 to L6) enclosed TDL phycobionts along with T. decolorans UTEX B781, whereas one of them (L7) enclosed TJL phycobionts along with $T$. jamesii UTEX 2233. Two lineages (L1 and L2) enclosed 70\% of the samples, haplotype (1) being the most represented in c.a. $20 \%$ of samples. We did not detect any direct relationship between the occurrence of certain algal lineages and their geographic location. However, we observed that lineage L1 was rather rare in samples growing on Quercus pyrenaica (only one out of 25 thalli from L1 algae), whereas it was very frequent in samples growing on the other studied phorophytes (Table 1). However, lineage L2 was frequently found on Q. pyrenaica (eight out of 11 thalli from L2 algae).

Apart from nrITS, a portion of the plastid 23S rDNA was amplified and sequenced using the 23SU1/23SU2 primer pair. Alignments of the obtained sequences (see Table S1 for accessions), revealed the existence of several short inserted sequence elements not found in other Trebouxia species (Fig. S1). The presence/

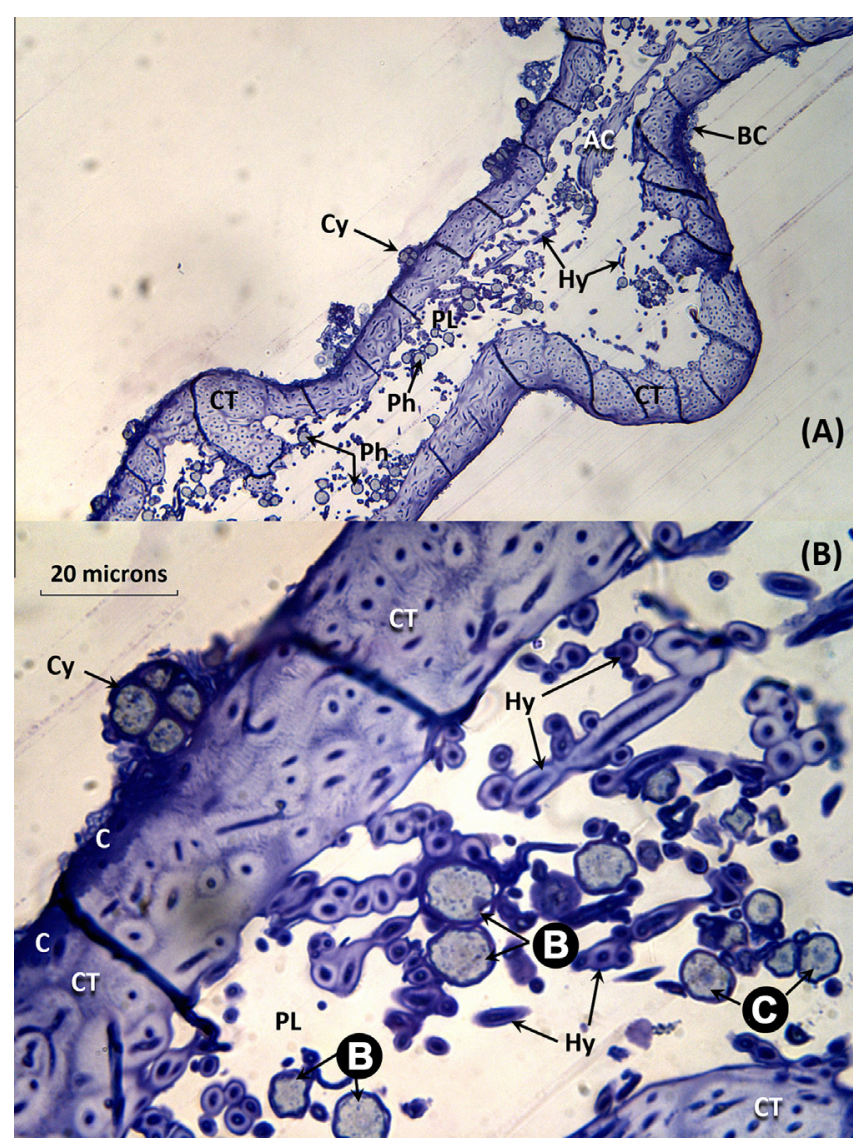

Fig. 1. Location by LM of two Trebouxia morphotypes (II and III in Fig. 2 and Table 2) in transverse sections of a Ramalina fraxinea thallus stained with toluidine blue. (a) Overview of the thallus; (b) details of the cortex and phycobiont layer. Abbreviations: AC: axial cord; BC: bacterial colonies; C: cortex; CT: chondroid tissue; Cy: cyanobacteria; Hy: hyphae; Ph: phycobiont; PL: phycobionts layer. (For interpretation of the references to color in this figure legend, the reader is referred to the web version of this article.)

absence, sequence and position of these inserted sequence elements varied greatly within samples and were as follows. (i) Four samples (M1, M4, R1, R4), showed two inserted sequence elements of $35 \mathrm{nt}$ (Fig. S1A): one near their $5^{\prime}$ end $\left(5^{\prime}-\right.$ GCT TCG CAA GAA GTG TGC GAA GCG TAG CTT CGC TC - $3^{\prime}$ ) and the other $562 \mathrm{nt}$ downstream ( $5^{\prime}$ - CGT GCG CAG CAA CGC TGC GCA CACT GCT CGC GCA G - 3'). (ii) Seven samples (AB6, J5, M5, M6, R5, R6, T5) had only the 35-nt inserted sequence element near their $5^{\prime}$-end. (iii) Four samples (AA1, AA3 VO1, VO3) and T. jamesii UTEX 2233 lacked the inserted sequence element near the $5^{\prime}$-end, but had an inserted sequence element of $23 \mathrm{nt}\left(5^{\prime}\right.$ - TGA CAA AGA CTC TGT TTT TGT TA $-3^{\prime}$ ) not present in other phycobionts. (iv) The remaining samples lacked these inserted sequence elements such as T. decolorans UTEX B781.

Complementarily amplification of a portion of the chloroplastencoded $p s b A$ gene with the psbAchl1/psbAchl2 primer pair rendered a variety of amplification products (see Table S1 for accessions). After sequencing, ten different versions of the $p s b A$ gene were obtained (Fig. S1B). Six of these versions had a group I intron inserted at position 569-570 in the psbA gene from Arabidopsis thaliana encoding ORFs with a maximum size of 248 codons. Only three versions of the $p s b A$ sequences lacked any intron and corresponded to either TDL: version $1 \mathrm{x}$ (sample J5) and version $2 \mathrm{x}$ (samples AB6, M5, M6, R5, R6 and T5) or TJL phycobionts: version 3x (AA3, VO1 and VO3). The corresponding mature mRNAs (after deleting introns) rendered six different versions (Fig. S1C). 

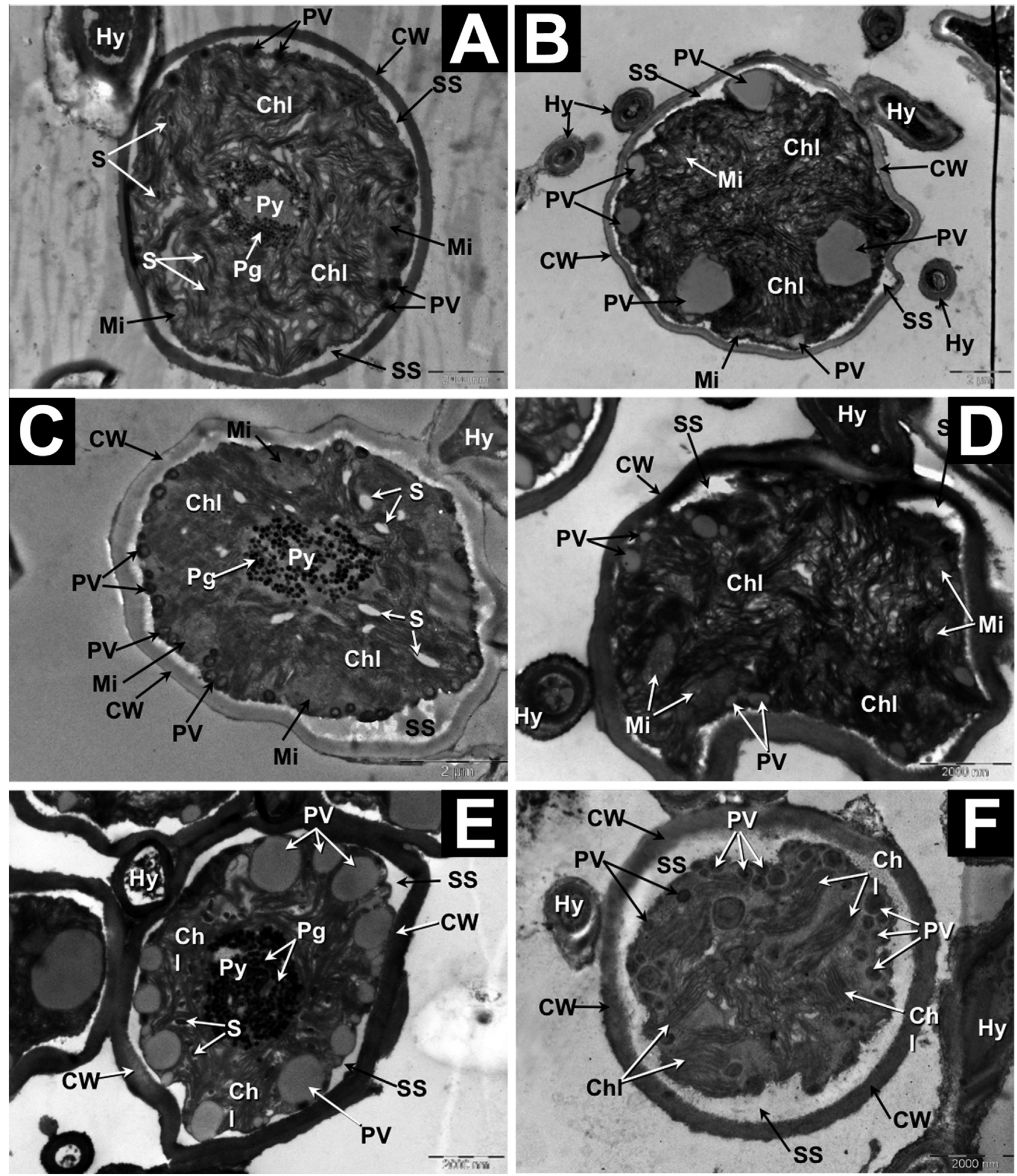

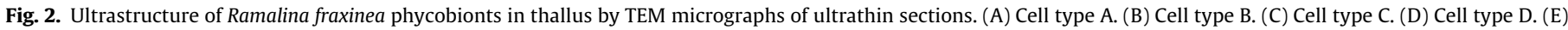

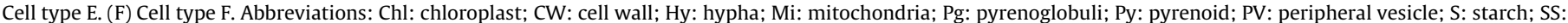
secretion space.

Phylogenetic relationships among phycobionts were studied on the basis of the combination of nuclear ITS and plastid 23S rDNA. The phylogram of Fig. 4 was constructed by aligning a total of 51 sequences, 50 from $R$. fraxinea phycobionts and one from $T$. decolorans UTEX B781. Samples AA1, AA3, VO1 and VO2 with TJL phyco- bionts (lineage L7), were selected as the out-group (Fig. 4). The resulting alignment included 1558 characters (including nucleotides and gaps or “-”), of which 1419 were constant and 133 were variable and parsimony informative. Two different phylogenetic analyses were performed (ML and Bayesian). The tree obtained 
Table 2

Morphological attributes of Ramalina fraxinea phycobionts.

\begin{tabular}{|c|c|c|c|c|c|c|}
\hline Morphological attributes & Type A & Type B & Type C & Type D & Type E & Type F \\
\hline Cell size (diameter, $\mu \mathrm{m}$ ) & $10.0 \pm 1.2$ & $10.1 \pm 1.6$ & $7.6 \pm 0.9$ & $8.4 \pm 1.6$ & $9.5 \pm 0.2$ & $7.3 \pm 2.0$ \\
\hline Cell wall (thickness, nm) & $334.8 \pm 23.2$ & $293.8 \pm 18.3$ & $305.2 \pm 50.5$ & $414.1 \pm 92.3$ & $422.2 \pm 19.1$ & $467.7 \pm 55.3$ \\
\hline Numbers of layers & 2 & 2 & 2 & 2 & 2 & 3 \\
\hline Chloroplast (number; shape) & 1; Lobated & 1; Lobated & 1; Lobated & 1; Lobated & 1; Lobated & Various \\
\hline Distribution of thylakoidal membranes & Light & Light & Dense & Light/dense (b) & Dense & Dense \\
\hline Arrangement of thylakoidal membranes & Untidy (a) & Untidy & Tidy & Tidy & Partially tidy & Tidy \\
\hline Number of membranes (stacking) & $2-3$ & $2-3$ & $3-4$ & $>3$ & $3-4$ & $>5$ \\
\hline Pyrenoid type & ge/ir & - & ir & - & ge/ir & - \\
\hline Pyrenoid size (diameter, $\mu \mathrm{m}$ ) & $2.8 \pm 0.4$ & - & $2.8 \pm 0.6$ & - & $3.7 \pm 0.2$ & - \\
\hline Pyrenoglobules (diameter, nm) & $79.3 \pm 6.0$ & - & $116.5 \pm 9.5$ & - & $127.4 \pm 4.6$ & - \\
\hline Matrix & Vesiculate & - & Dense & - & Dense & - \\
\hline Mitochondrion (number) & Scarce & Scarce & Scarce & Abundant & Scarce & Few \\
\hline Mit. size (length, nm) & $1076.9 \pm 293.9$ & $633.2 \pm 68.3$ & $848.2 \pm 151.5$ & $1160.2 \pm 78.9$ & $1214.8 \pm 453.8$ & $1318.2 \pm 197.9$ \\
\hline Mit. size (width, nm) & $553.1 \pm 129.5$ & $322.3 \pm 37.1$ & $590.7 \pm 119.2$ & $640.4 \pm 92.9$ & $619.0 \pm 103.2$ & $564.3 \pm 58,1$ \\
\hline Peripheral vesicles, number of types (c) & Numerous, ED & Numerous, NED & Numerous, ED & Numerous NED & Numerous NED & Numerous NED \\
\hline Vesicles (diameter, nm) & $364.7 \pm 83.6$ & $1799.3 \pm 284.0$ & $553.7 \pm 80.3$ & $458.2 \pm 80.4$ & $1110.1 \pm 253.3$ & $1151.2 \pm 144.2$ \\
\hline Vesicles (diameter, nm) & - & $777.8 \pm 106.5$ & $288.9 \pm 65.5$ & $214.9 \pm 43.9$ & - & $625.7 \pm 100.2$ \\
\hline Starch (lenticular form) & + & - & + & - & + & - \\
\hline Length & $269.3 \pm 47.6$ & - & $383.4 \pm 78.3$ & - & $313.9 \pm 13.8$ & - \\
\hline Width & $91.4 \pm 13.3$ & - & $161.3 \pm 27.3$ & - & $139.5 \pm 27.2$ & - \\
\hline Abundance & + & - & +++ & - & ++ & - \\
\hline Type & Blackish & - & White & - & Blackish & - \\
\hline Secretion space & Present, narrow & Present, narrow & Present & Present & Present & Wide \\
\hline Thalli sample & M1, M4, M5 and T1 & AA1, M1 and M5 & $\mathrm{AA} 1, \mathrm{M} 4$ and M5 & M1 & AA5 & M4 \\
\hline
\end{tabular}

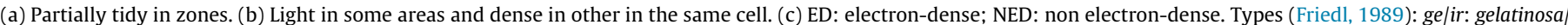
irregularis, ir: irregularis.

had a Consistency Index (CI) of 0.9317 , which indicated high reliability in the phylogenetic reconstruction. Sample J5 was not included in the phylogeny of Fig. 4 because of some discrepancies in assigning the correct algal lineage on the basis of molecular markers (the 23S rDNA sequence was compatible with L3 and L4, but nrITS sequences corresponded to L6). In this phylogeny, two main clades with support values of 1 and 100 (for Bayesian and ML analyses, respectively) can be distinguished. Clade I was made up of 11 samples with high support values ( 1 and 90 for Bayesian and ML analyses, respectively), which corresponded to lineage L2. Clade II was comprised of most of the $R$. fraxinea samples (35) with high support values ( 1 and 100 for Bayesian and ML analyses, respectively). This clade included four algal lineages (L1, L3, L4 and L5). Lineage L1 is the most represented with 25 samples including $T$. decolorans UTEX B781.

Along with phycobiont diversity, the variability of mycobiont genotypes was examined based on two different fungal loci: nrITS (fits) and beta-tubulin (bet). The sequences corresponding to these two loci were determined in the thalli indicated in Table S2. To make an estimate of relationships among fungal haplotypes, we used the program TCS 1.21 (Clement et al., 2000). The genealogy depicted in Fig. 3B was built based on 49 aligned sequences resulting from the combination of both fits and tub sequences from the studied specimens of $R$. fraxinea (Tables 1 and $\mathrm{S} 2$ ). As shown in Fig. 3B, 23 different fungal haplotypes were included in a single network indicating that all the analyzed samples belonged to the same lichen species. Among the 23 fungal haplotypes, two of them (haplotypes 1 and 13) were the most common, being present in more than one third of the analyzed thalli.

\subsection{Coexistence of different Trebouxia genotypes within a single thallus}

To test the possible coexistence of more than one phycobiont type in a single thallus, molecular analyses with different primer pair combinations were performed. Amplification of the $p s b A$ gene with the psbAchl1/psbAchl2 primer pair (del Campo et al., 2010a), revealed the presence of two bands of c.a. 1500 and $700 \mathrm{nt}$ per sample (Fig. 5A). After sequencing both bands, we found that the largest one included a group I intron inserted at position 569570 in the same gene from Arabidopsis thaliana, whereas the smallest band corresponded to the same portion of the $p s b A$ gene without an intron (Fig. 5C). Since the $p s b A$ gene is chloroplast-encoded, there is a single sequence of this gene even if it is duplicated in the inverted repeats of the corresponding cpDNA. Thus, the presence of two variants of the $p s b A$ genes within the same thallus can only be explained by the co-existence of two different phycobionts. This finding was consistent with the coexistence of more than one morphologically-different phycobionts within the same thallus (Table 2). Complementary analyses based on the 23SrDNA gene with the 23S-Tj1/23S-Tj2 primer pair, which amplified the cL2263 intron present in the 23SrDNA of T. jamesii (UTEX 2233) and Trebouxia. sp. TR1 phycobionts from R. farinacea (Casano et al., 2011), rendered three different patterns (Fig. 5B): (i) a single band of c.a. 1200 nt (lane AA1 in Fig. 5B), (ii) a single band of c.a. 300 nt (lanes AB1-3 and AC1-2 in Fig. 5B) and (iii) two bands of c.a. $1200 \mathrm{nt}$ and $300 \mathrm{nt}$ (lane AA3 in Fig. 5B). The sequence of the DNA bands of c.a. $1200 \mathrm{nt}$ and $300 \mathrm{nt}$ were identical to that of T. jamesii (UTEX 2233) (del Campo et al., 2010b), and similar to T. decolorans (UTEX B71) corresponding to TJL and TDL phycobionts in Fig. 5, respectively. These findings indicated: (i) the presence of TJL phycobionts in samples rendering a band of c.a. $1200 \mathrm{nt}$; (ii) the presence of TDL phycobionts in samples rendering a band of $300 \mathrm{nt}$; and (iii) the presence of both TJL and TDL phycobionts in samples rendering both bands (Fig. 5B).

Additionally, some discrepancies were found in assigning the algal lineages to each sample based on each of the three markers (nrITS, 23S rDNA and psbA). In J5 the 23S rDNA sequence was compatible with $\mathrm{L} 3$ and $\mathrm{L} 4$, but nrITS and $p s b A$ sequences corresponded to L6. In AA1 the 23S rDNA and nrITSA sequences corresponded to 
A
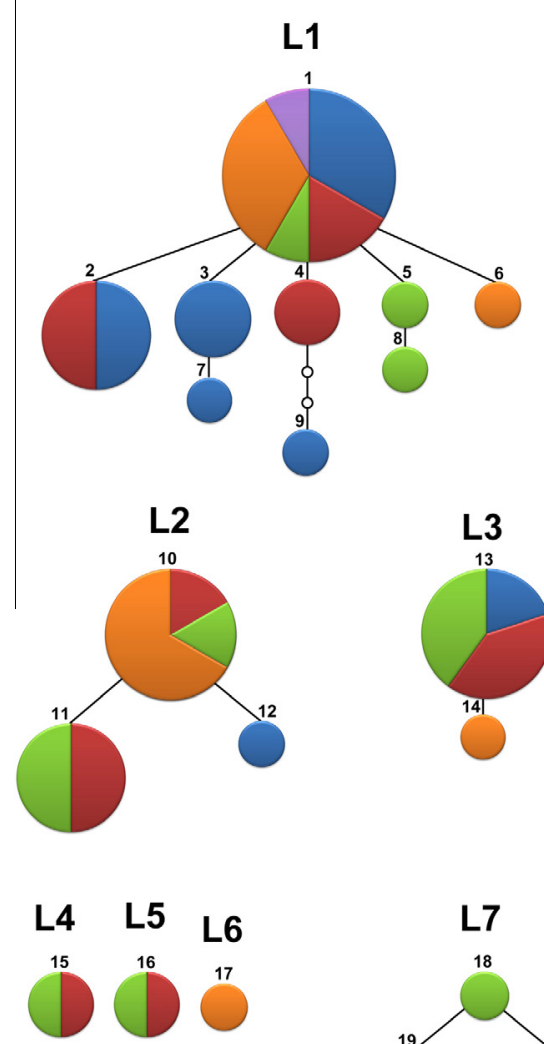

L3

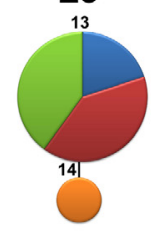

L7

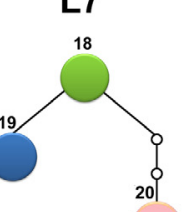

B

\section{Mycobiont}

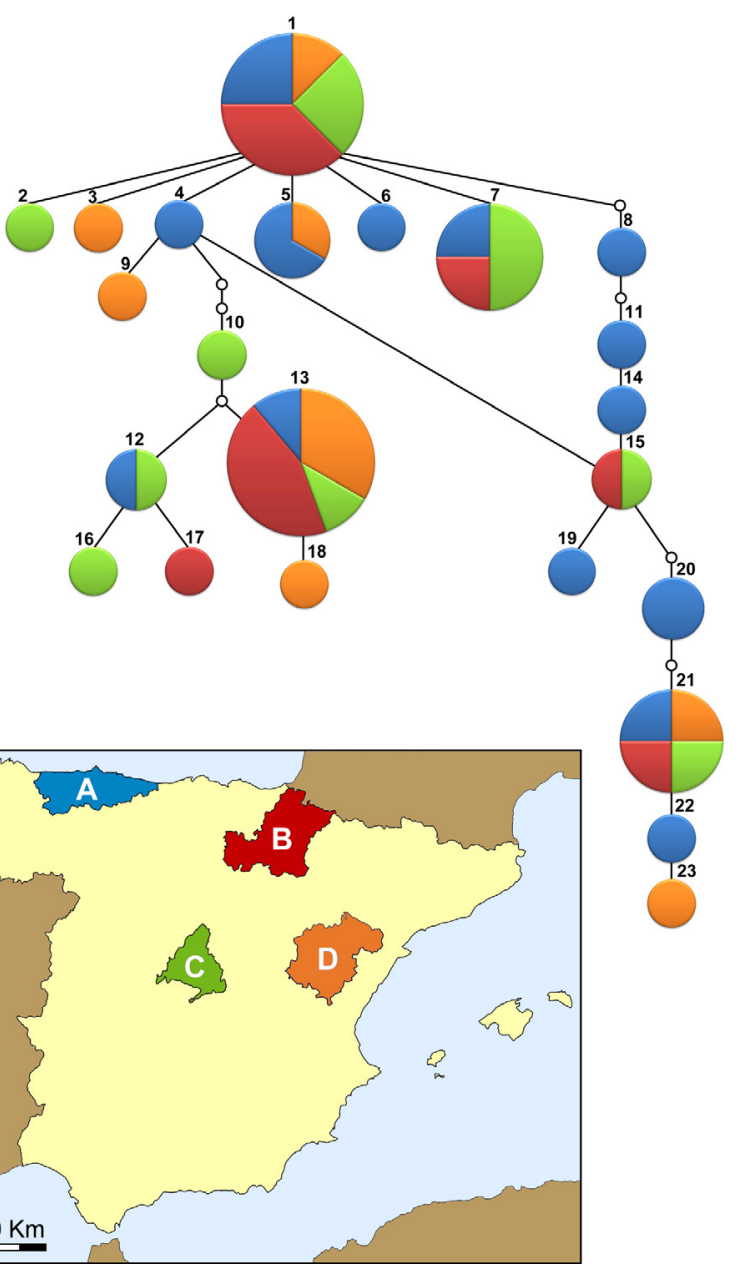

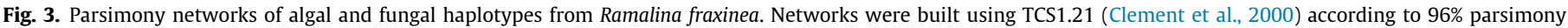

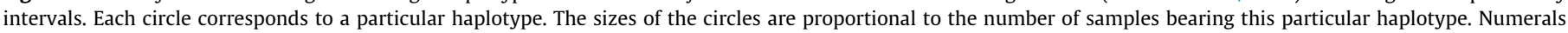

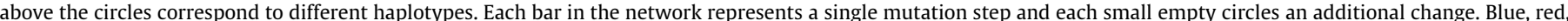

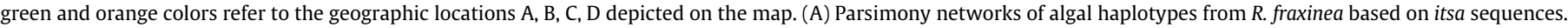

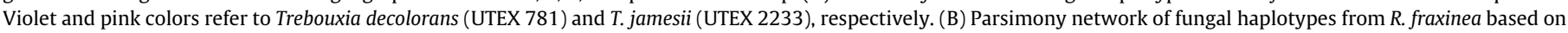
combined fungal fits/btub sequences. (For interpretation of the references to color in this figure legend, the reader is referred to the web version of this article.)

L7, but the $p s b A$ sequence corresponded to L1. In VP3 the 23S rDNA and nrITSA sequences corresponded to L1, but the $p s b A$ sequence corresponded to L2. These discrepancies were interpreted as indirect evidence of the possible coexistence of several different lineages of Trebouxia algae within the same thallus.

\subsection{TDL algal lineages are shared by different lichen taxa}

After defining the different algal haplotypes for each sampled thallus of $R$. fraxinea, we searched for nrITS haplotypes similar to those of each TDL algal lineage (L1 to L6) in the NCBI nucleotide database. Fig. 6 shows a phylogenetic reconstruction based on the nrITS sequences of phycobionts closely related to TDL phycobionts from $R$. fraxinea. The phylogram was constructed by aligning a total of 126 sequences including sequences from $T$. jamesii UTEX 223 (accession FJ626733), samples AA1, AA3, VO1 and VO3 from $R$. fraxinea and TR1 from $R$. farinacea (accession FJ418566) as the outgroup. The resulting alignment included 565 characters (including nucleotides and gaps or “-”), of which 436 were constant and 104 were variable and parsimony informative. Two different phyloge- netic analyses were performed (ML and Bayesian). The tree obtained had a Consistency Index (CI) of 0.8020 , which indicated high reliability in the phylogenetic reconstruction. In this phylogeny, we distinguished eight clades/lineages as being consistent with the phylogram of Fig. 4. Lineage L1 was the most represented with 82 samples including $T$. decolorans UTEX B71 (accession FJ626728): 27 from $R$. fraxinea, 38 from Xanthoria parietina, 9 from Anaptychia ciliaris and 7 from other lichen species. L2 had 12 representatives: 11 from $R$. fraxinea and one from $X$. parietina. L3 had 9 representatives: 6 from $R$. fraxinea, 2 from Xanthoria, and one from A. ciliaris. L4 had only 2 representatives from $R$. fraxinea and one from A. ciliaris. L5 had only 2 representatives from $R$. fraxinea. $\mathrm{L} 6$ had a single representative from $R$. fraxinea found in this study (sample J5). Two additional lineages, L8 an L9 did not include any sequences from $R$. fraxinea, but all them were closely related to lineages L1, L3, L4, L5 and L6. These lineages included sequences from Ramalina menziesii and X. parietina (L8) and X. parietina, Caloplaca spp. and Seirophora villosa (L9). In conclusion, Xanthoria parietina (L.) Th. Fr. was identified as the lichen species, which shared most of the algal lineages of $R$. fraxinea (lineages L1, L2 


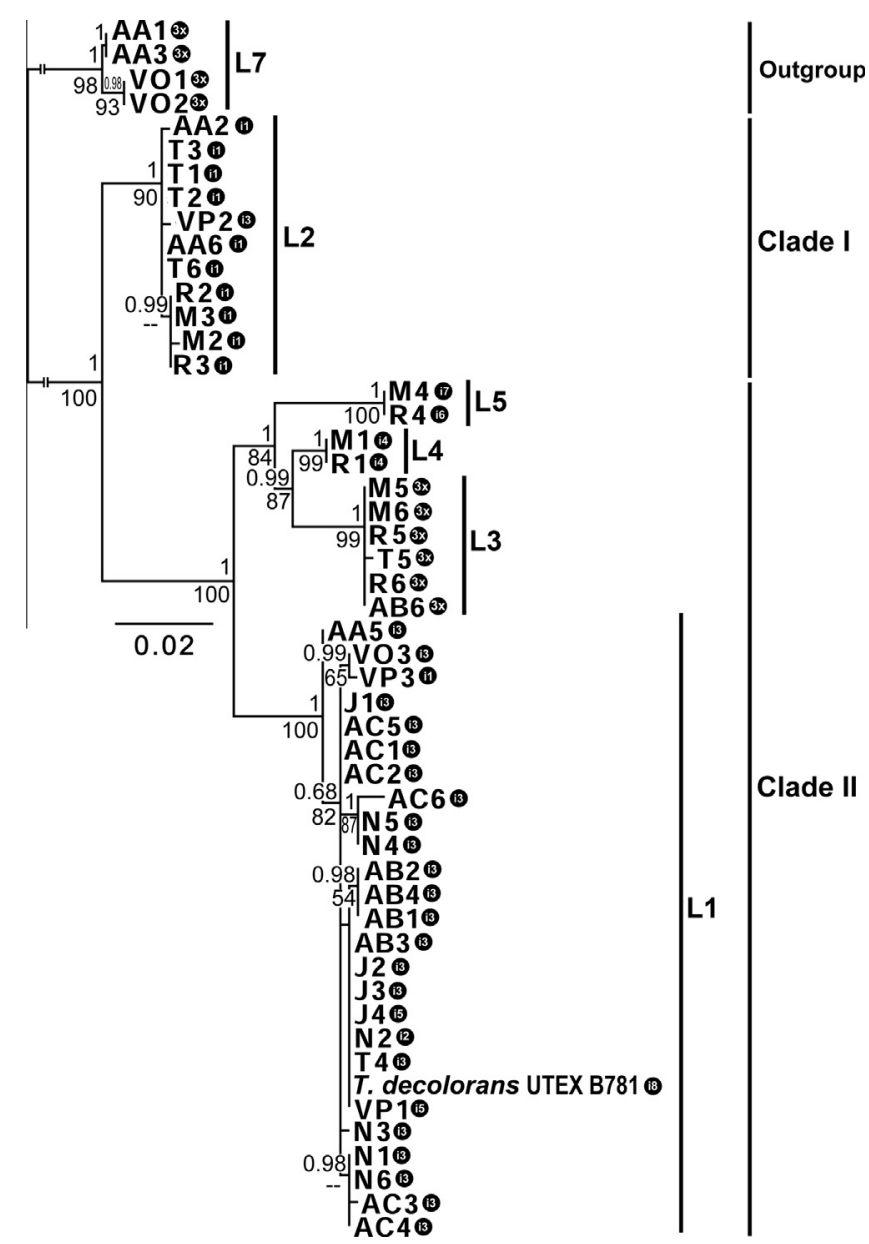

Fig. 4. Phylogram based on the analysis of combined sequences of algal nrITS and chloroplast 23S rDNA from Ramalina fraxinea phycobionts. The sequences of TJL phycobionts were used as out-group (AA1, AA3, VO1 and VO2). Tip labels correspond to each sample of Table 1 . Internal vertical bars indicate different algal lineages (L1 to L7). Group I introns within the psbA gene are indicated with an "i" symbol followed by a number (to distinguish between different sequences) within black circles to the right of each sample name. Absence of introns is indicated with an " $x$ " symbol followed by a number (to distinguish between different coding sequences) within black circles to the right of each sample name. Values over and below the branches correspond to posterior probabilities and bootstrap values after Bayesian and ML analyses, respectively. Bootstrap values were recorded only for those lineages supported by at least $50 \%$ of all (100) replicates. The scale bar indicates substitutions/site. TJL are Trebouxia jamesii like phycobionts. Sample J5 was not included in the phylogeny because of some discrepancies in assigning the correct algal lineage on the basis of molecular markers (the 23S rDNA sequence was compatible with L3 and L4, but nrITS sequences corresponded to L6).

and L3 in Fig. 6) along with Anaptychia ciliaris (lineages L1, L3 and L4 in Fig. 6). Ramalina menziesii had phycobionts enclosed within a separate lineage L8 (Fig. 6), which was closely related to lineage L6 from Ramalina fraxinea. Finally, some phycobionts from Caloplaca spp. and Seirophora villosa where enclosed within lineage L9, which was less closely related to the remaining lineages of Fig. 6.

\section{Discussion}

The present study contributes to our understanding of the plasticity of symbiont associations in lichens. We provide not only morphological and molecular evidence of the presence of at least seven different Trebouxia lineages associating with $R$. fraxinea mycobionts, but we also detected the presence of more than one (usually 3 ) of these lineages within the same thallus. This assumption was supported by several pieces of evidence: (i) the finding of several morphotypes within the same sample (Table 2 and Fig. 2); (ii) the amplification of at least two different forms of the chloroplast $p s b A$ gene corresponding to two different algal lineages with DNA from a single thallus (Fig. 5A); (iii) the amplification of two or three different sized bands from the chloroplast 23S rDNA gene in a single thallus (Fig. 5B); and (iv) discrepancies in lineage assignments based on both morphological features and the sequences of each of the three markers obtained from a single thallus in several samples. Additional analyses of nrITS sequences with the primer pair ITS-TR1f/ITSTR1r (Casano et al., 2011) specific for nrITS of Trebouxia sp. TR1 from R. farinacea and T. jamesii (UTEX 2233) rendered the corresponding amplification product in all the studied samples (data not shown). This result indicated the presence of TJL phycobionts in all the studied thalli.

The morphological analyses were mainly based on chloroplast and pyrenoid ultrastructures in vegetative cells inside the lichen thallus. The pyrenoid ultrastructure was well established as a taxonomic character in Trebouxia algae by Friedl (1989). However, one pyrenoid group does not necessarily represent one species since similarities in pyrenoid morphology also frequently occur within rather different groups of algae (Geitler, 1926). Moreover, cultured and lichenized phycobionts show virtually the same pyrenoid morphology, which allows for the identification of Trebouxia pycobionts without culturing by comparing the pyrenoid structure (Friedl, 1989).

In this study we determined the presence of at least six Trebouxia morphotypes, and the possible coexistence of up to four of them, as in the case of sample M1, in which morphotypes A, B, D and F can be observed (Table 2). Only three of the Trebouxia lineages detected in Ramalina fraxinea exhibit pyrenoid, while morphotype C shows a clear fine structure of the irregularis type, morphotypes A and $\mathrm{E}$ seem to have transitional features between the types gelatinosa and irregularis which is a novelty not described in the literature (Fig. 2, Table 2). As such, pyrenoid structure can be used as taxonomic character only in these three morphotypes. Morphotypes B, D and F do not show any clear pyrenoid, and this characteristic was not designated for Trebouxia algae, but for the provisionally named Trebouxia sp. TR9 found in Ramalina farinacea, closely related to $T$. jamesii, never shows pyrenoid structures while the second one has the impressa-type (Casano et al., 2011). Further characteristics such as chloroplast morphology have to be considered for identification by TEM or confocal microscopy. The problem is that very scarce documentation has been published on these features, especially in a symbiotic state, making it difficult to discuss the types of chloroplasts we have found in the chlorobionts of Ramalina fraxinea. The morphotypes D, E and F had thick cell walls of more than $400 \mathrm{~nm}$. After the studies recently published by Casano et al. (2015) point out that the ultrastructure and thickness of the cell walls, at least in symbiosis should be considered in the future.

In the genus Trebouxia there is not any clear species concept mainly due to the serious problems in identifying and delimiting species on the basis of morphological characters. The use of ultrastructural traits such as chloroplasts and pyrenoids traditionally used to characterize species within the genus Trebouxia (Friedl, 1989), do not always allow for clear species delimitations. DNA sequences are increasingly being used for species identification (DNA barcoding), species discovery and delimitation (DNA taxonomy), and for testing/corroborating traditional species-level taxonomies (Wiens, 2007). Recent developments in DNA-based sequence delimitation of species boundaries in algae have been recently discussed (Leliaert et al., 2014). At present, nrITS sequences continue to be the most commonly used molecular markers for phylogenetic reconstructions among lichen microalgae (Muggia et al., 2013; Nelsen and Gargas, 2008; Piercey-Normore, 2006; Škaloud and Peksa, 2010). However, molecular studies based solely on algal nrITS sequences, sometimes lead to an 
A

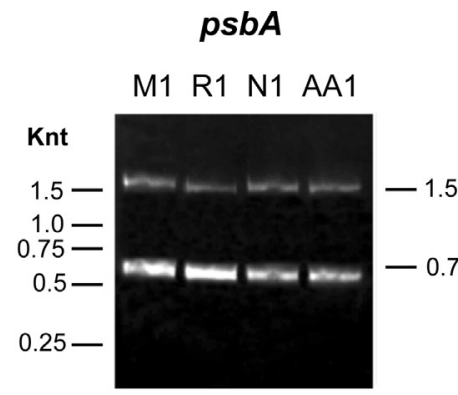

(psbAchl1/psbAchl2)
B

\section{S rDNA}

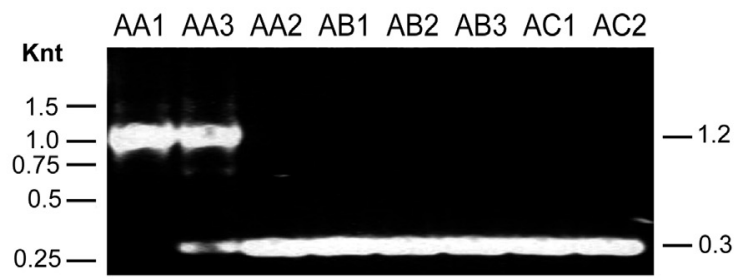

(23S-Tj1 / 23S-Tj2)

C

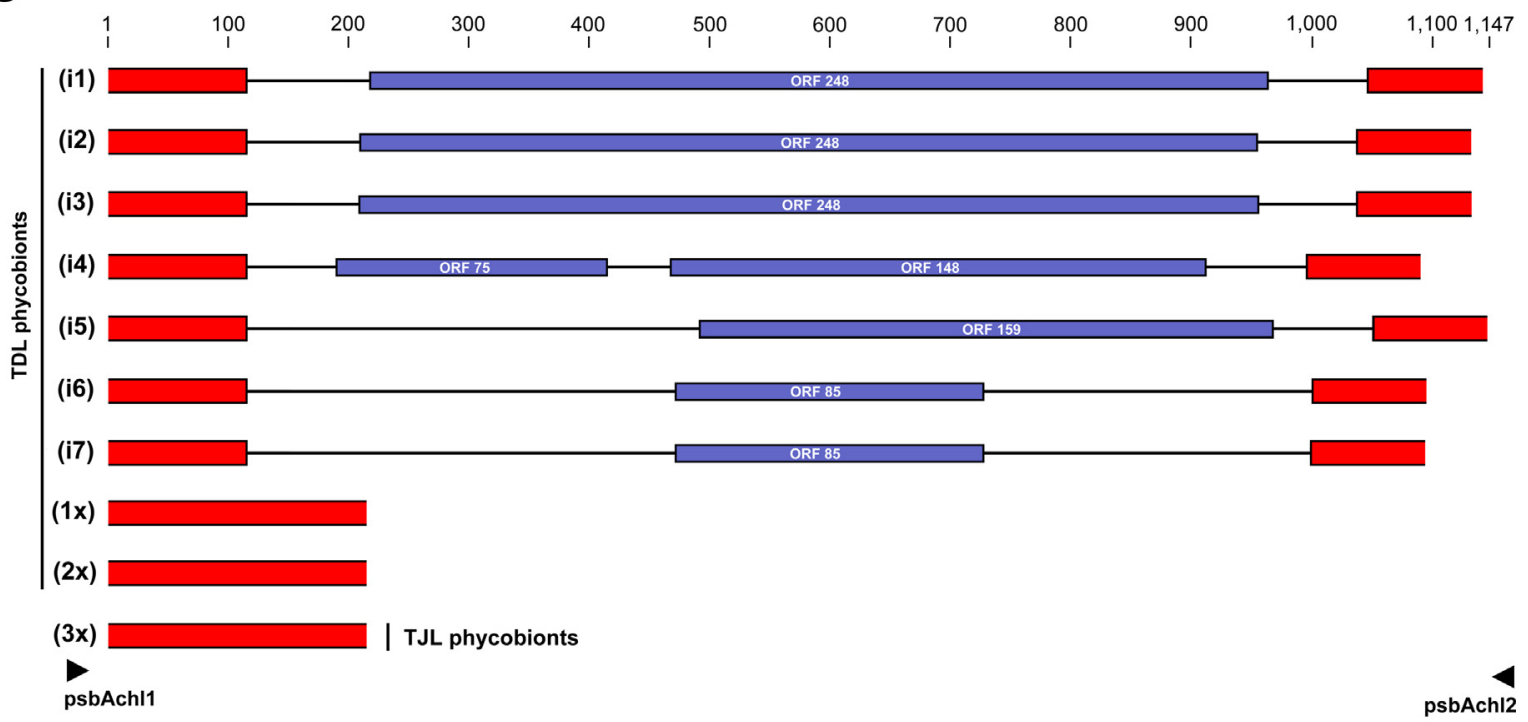

D

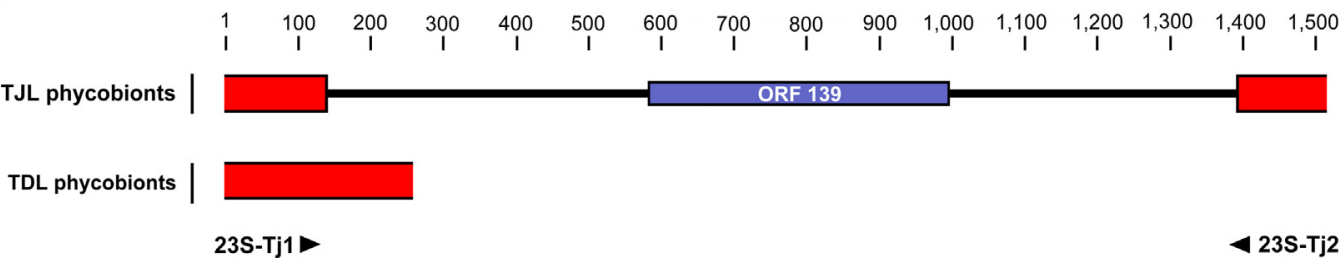

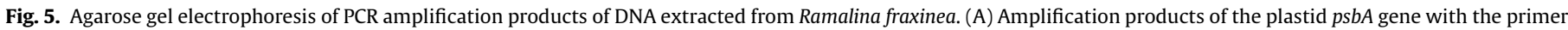

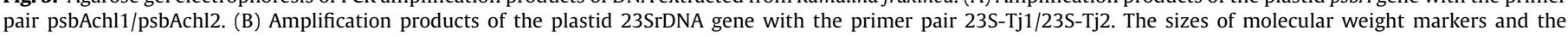

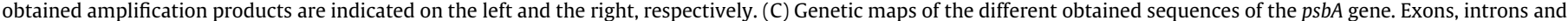

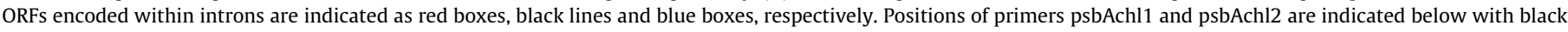

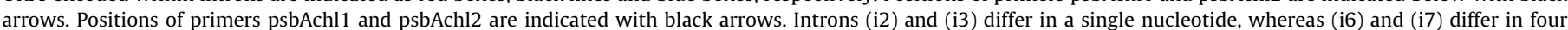

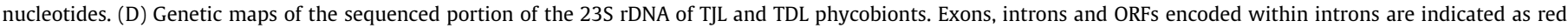

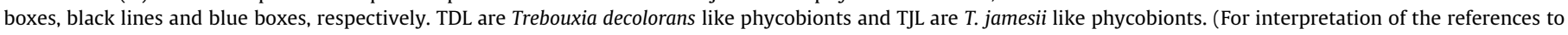
color in this figure legend, the reader is referred to the web version of this article.)

underestimation of phycobiont diversity within certain lichen species. Methods based on single-locus data rely on the assumption that a single gene genealogy is representative of the species phylogeny. Given the prevalence of undiscovered and cryptic species in many algal groups, any marker chosen as a DNA barcode should preferably be suitable not only for species identification, but also for species delimitation and discovery (Leliaert et al., 2014). In Asterochloris algae, evolutionary inferences based on two or three molecular markers (ITS rDNA, actin, LSU rDNA sequences) revealed extensive diversity of this algal genus with amazing cryptic variability (Moya et al., 2015; Škaloud and Peksa, 2010; Škaloud et al., 2015). The same study revealed the misclassification of several Trebouxia species (T. erici, T. excentrica,
T. glomerata, T. irregularis, T. italiana and T. magna) that have been transferred to Asterochloris (Škaloud and Peksa, 2010) as previously suggested (Rambold et al., 1998). Recently, the use of additional molecular tools revealed the harboring of several phycobiont strains per thallus in X. parietina and A. ciliaris (Dal Grande et al., 2014), and $R$. farinacea (Casano et al., 2011).

In our study, evolutionary inferences based on multiple loci: either nuclear (nrITS) or chloroplast-encoded (23S rDNA and the $p s b A$ gene) revealed the unexpected cryptic variability of Trebouxia algae associating with Ramalina fraxinea, which seem compatible with the morphological variability discussed in previous paragraphs. We tried to integrate molecular and morphological data in order to assign a lineage to each morphotype. However, 


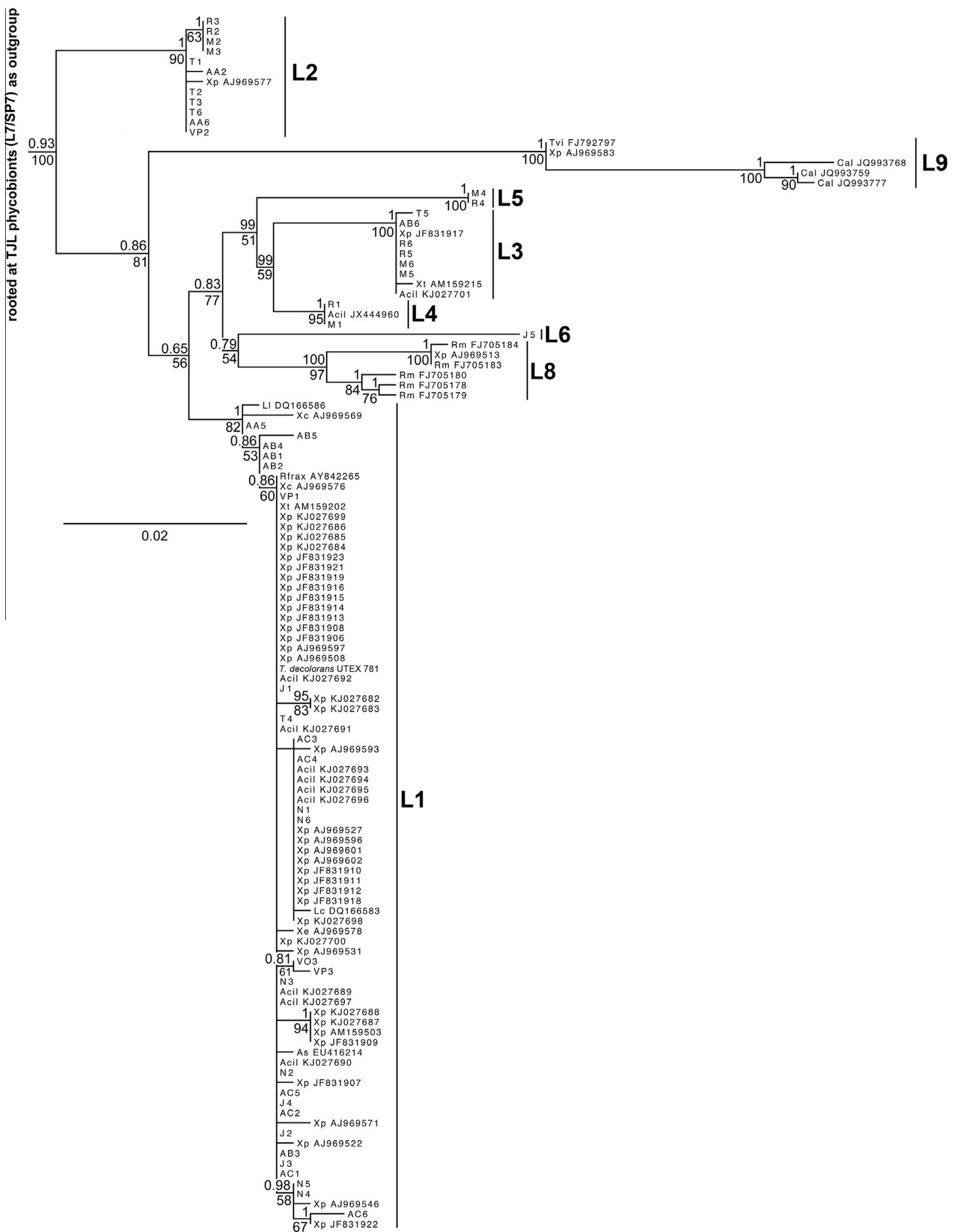

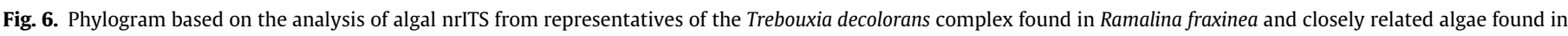

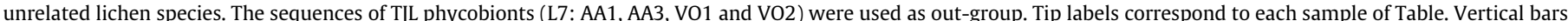

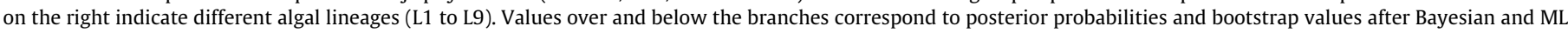

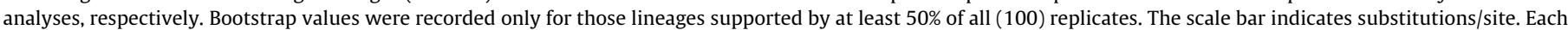

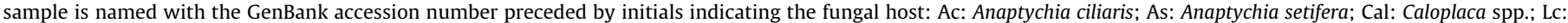

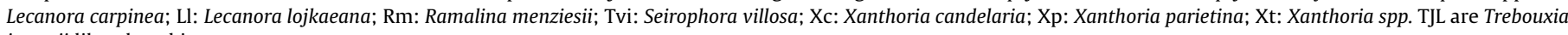
jamesii like phycobionts. 
we obtained contradictory results. On the one hand, samples AA5 and $\mathrm{T} 1$ belonged to lineages L1 and L2 according to molecular data (Figs. 4 and 6) and had a single phycobiont of type E (Fig. 2E) and A (Fig. 2A), respectively. This observation may allow for provisionally associating lineages $\mathrm{L} 1$ and $\mathrm{L} 2$ with morphotypes $\mathrm{E}$ and $\mathrm{A}$, respectively. On the other hand, sample AA1 was associated with two different phycobiont lineages depending on the molecular marker used: lineages L6 (according to nrITS sequences and the chloroplast psbA gene) and L7 (according to the chloroplast 23SrDNA). This sample also showed two morphotypes: type B and C. Thus, it may be possible that morphotypes $B$ and $C$ corresponded to lineages L2 and L7, respectively. However, this second conclusion is in conflict with the first conclusion of correspondence between lineage L2 and morphotype A. These discrepancies in assigning morphotypes to lineages integrating both morphological and molecular approaches suggested that: (i) samples in which a single morphotype has been found such as AA5 and T1, the observed morphotype may be the most common within the analyzed thallus, but probably is not the only one present; and (ii) observation of certain morphotypes in each sample does not necessarily mean that there are not more types that we have not seen. This emphasizes the need to isolate cells in individual axenic cultures to gain reliable assignments of each nucleotide sequence to a specific morphotype. We are trying to develop a new methodology for isolation, identification and fast growth for lichen algae in samples with several lineages, but we need to improve upon various phases (Molins et al., 2015).

The different morphological features of each cell type (Fig. 2) along with the phylogenies of Figs. 4 and 6, suggested the idea that they may correspond to different Trebouxia lineages, or even species. However, we must be careful with this assumption since it is known that many algal species can exhibit substantial intraspecific morphological variation, either as a result of genetically controlled polymorphism or environmentally induced plasticity [e.g., (de Senerpont Domis et al., 2003; Logares et al., 2007)]. Ignoring intraspecific morphological variation may result in an overestimation of species diversity. The association of Ramalina fraxinea with at least seven different Trebouxia lineages (Figs. 3 and 6) reflects the low selectivity of the mycobiont. Lineage L1, which included Trebouxia decolorans UTEX B781, was the most common phycobiont in Ramalina fraxinea, being present in approximately $50 \%$ of the analyzed lichen thalli (Fig. 4). Similarly, in Xanthoria parietina this Trebouxia species seems to be the most common phycobiont (Nyati et al., 2014). In both cases, the predominance of lineage L1 seems to be independent of the geographic location. Interestingly, the ultrastructure of $X$. parietina thalli (Molina and Vicente, 1996) shows a Trebouxia phycobiont with a central pyrenoid with abundant well-defined pyrenoglobuli and thylakoids associated in groups within the chloroplast. Big vesicles forming a complex were located in the surrounding zone of plasmalemma, close to some storage bodies, which were very dense to electrons. Such features are shared by morphotype E. Since lineage $\mathrm{L} 1$ is the most abundant in X. parietina (36 samples in Fig. 6) than lineages L2 and L3 (a single sample each of them in Fig. 6), it is possible that morphotype E corresponded to lineage L1.

The nrITS sequences from lineage L1 are the most common in GenBank accounting for 82 accessions (Fig. 6). This lineage was widespread and present in samples from Europe, the United States, Asia and New Zealand, and associated with a wide range of fungal species such as $R$. fraxinea, X. parietina (and other Xanthoria species), Anaptychia (A. ciliaris and A. setifera) and Lecanora (L. carpinea and $L$. lojkaeana). However a few nrITS sequences were found to correspond to the remaining TDL lineages present in $R$. fraxinea. It is possible that all these observations could be the result of biased sampling represented in GenBank, especially in the case of the sorediate species (mainly crusts), that may distribute these algae from place to place and which have been seriously understudied, preventing us from seeing/understanding the main drivers of this community-level symbiotic system (Rikkinen, 2003).

Interestingly, lichens including Trebouxia algae form the lineage L1 as phycobiont bear conspicuous apothecia containing the asci that in turn contain and release the sexual ascospores that can facilitate long-distance gene movement and reshuffling of the genotypic combinations of partners (Dal Grande et al., 2012; O'Brien et al., 2013). Sexual reproduction with obligate crossfertilization (heterothallism) (Honegger and Zippler, 2007) facilitates successful re-lichenizations by allowing higher flexibility in the specificity and ecological selection of their phycobionts. Many different lichen-forming fungi, even from different genera or even families, can often associate and potentially share specific photobiont strains. Many lichen-forming fungi seem to form photobiont-mediated guilds, i.e., co-occurring species populations containing the same photobiont strain (Rikkinen, 2007). Some guild members may even depend on other fungal species for the effective dispersal of their photobionts. Lichen guilds may have begun as a pairwise interaction between two members that may have evolved by collecting additional symbionts and losing others. For lichen-forming fungi, each successful shift into a new guild provided new opportunities for speciation and subsequent radiation (Rikkinen, 2007).

Trebouxia decolorans Ahmadjian is a widespread and common symbiotic green alga whose association with many lichenforming fungi has been reported. Some examples are Ramalina menziesii (Werth and Sork, 2010), Caloplaca spp. (Vargas Castillo and Beck, 2012), Seirophora villosa (Royo et al., 2009), Xanthoria parietina (Beck and Mayr, 2012; Dal Grande et al., 2014; Nyati et al., 2014) and Anaptychia ciliaris (Dal Grande et al., 2014). It is known that Trebouxia decolorans isolated from Xanthoria parietina turns colorless at high light intensities as consequence of a deficiency in carotenoids (Ahmadjian, 1960). The bleached cells may restore their color in darkness under heterotrophic conditions. Regarding their photosensitivity, Trebouxia decolorans cells could not survive free-living for a long time (Rikkinen, 1995). This means that the cells of this Trebouxia species probably depend on the photoprotection of the fungal partner for their survival. It has been suggested that in lichens that have more than one strain of Trebouxia in their thalli, including Trebouxia decolorans, this algal species could exist as a commensalist or parasite (e.g. Rikkinen, 1995). This contrasts with the conventional view of lichens as associations of autotrophic algae and heterotrophic fungi. We propose the hypothesis that in lichens associating with at least two different Trebouxia species, including Trebouxia decolorans, such as Ramalina fraxinea (this study) and Xanthoria parietina (Dal Grande et al., 2014), T. decolorans may be either directly or indirectly nutritionally supported by other coexisting Trebouxia species. This new view of lichens adds more complexity to the relationships among different types of organisms inhabiting within "lichen micro-ecosystems". Firstly, lichens may be considered not only as associations between a mycobiont with a single phycobiont, but in associations between a mycobiont with more than one strain/species of phycobiont. Secondly, lichens may be considered not only as mutualistic associations since they can include commensalism and even parasitism as possible relationships. Thirdly, in microbial communities within lichens we must take into account not only the concept of compatibility between the mycobiont and the photobiont/s, but also the compatibility between the different coexisting photobiont strains/species. Fourthly, it should be also considered the interactions among mycobiont, photobiont(s) and the abundant and diverse bacterial symbiotic community which makes also part (Aschenbrenner et al., 2014).

From all of these results taken together, we can conclude that coordinated ultrastructural and molecular analyses are suitable 
for improving estimates of diversity and further reveal the coexistence of more than one Trebouxia species within the same thallus. However, it is difficult to integrate the obtained data in order to assign particular morphotypes to genotypes/lineages and understand the biological significance of the obtained data. For future investigations, we propose the isolation of each identified phycobiont in order to more confidently associate each morphotype with its DNA signature. Additional experimental approaches will be necessary to study the physiological performance of the identified phycobionts in different environmental conditions to gain knowledge about the possible relationships between the mycobiont and each phycobiont, along with the relationships among the coexisting phycobionts. It is also necessary to develop clearer species delimitation criteria within the genus Trebouxia and microalgae in general.

\section{Acknowledgments}

This study was funded by the Ministerio de Economía y Competitividad (MINECO CGL2012-40058-C02-01/02), FEDER, the Generalitat Valenciana (PROMETEOII2013/021, GVA) and the Dirección General de Universidades e Investigación de la Consejería de Educación de la Comunidad de Madrid - Universidad de Alcalá (CCG10-UAH/GEN-5904). Drs. Arantxa Molins and Patricia Moya (Universitat de València) made helpful comments on the manuscript.

\section{Appendix A. Supplementary material}

Supplementary data associated with this article can be found, in the online version, at http://dx.doi.org/10.1016/j.ympev.2015.10. 021.

\section{References}

Ahmadjian, V., 1960. Some new and interesting species of Trebouxia, a genus of lichenized algae. Am. J. Bot. 47, 677-683.

Altschul, S.F., Madden, T.L., Schaffer, A.A., Zhang, J., Zhang, Z., Miller, W., Lipman, D.J., 1997. Gapped BLAST and PSI-BLAST: a new generation of protein database search programs. Nucl. Acids Res. 25, 3389-3402.

Álvarez, R., del Hoyo, A., Díaz-Rodríguez, C., Coello, A.J., del Campo, E.M., Barreno, E., Catalá, M., Casano, L.M., 2015. Lichen rehydration in heavy metal-polluted environments: $\mathrm{Pb}$ modulates the oxidative response of both Ramalina farinacea thalli and its isolated microalgae. Microb. Ecol. 69, 698-709.

Aschenbrenner, I.A., Cardinale, M., Berg, G., Grube, M., 2014. Microbial cargo: do bacteria on symbiotic propagules reinforce the microbiome of lichens? Environ. Microbiol. 16, 3743-3752.

Beck, A., Mayr, C., 2012. Nitrogen and carbon isotope variability in the green-algal lichen Xanthoria parietina and their implications on mycobiont-photobiont interactions. Ecol. Evol. 2, 3132-3144.

Blaha, J., Baloch, E., Grube, M., 2006. High photobiont diversity associated with the euryoecious lichen-forming ascomycete Lecanora rupicola (Lecanoraceae, Ascomycota). Biol. J. Linn. Soc. 88, 283-293.

Buschbom, J., Mueller, G.M., 2006. Testing "species pair" hypotheses: evolutionary processes in the lichen-forming species complex Porpidia flavocoerulescens and Porpidia melinodes. Mol. Biol. Evol. 23, 574-586.

Casano, L.M., Braga, M.R., Álvarez, R., del Campo, E.M., Barreno, E., 2015. Differences in the cell walls and extracellular polymers of the two Trebouxia microalgae coexisting in the lichen Ramalina farinacea are consistent with their distinct capacity to immobilize. Plant Sci. 236, 195-204.

Casano, L.M., del Campo, E.M., García-Breijo, F.J., Reig-Armiñana, J., Gasulla, F., Del Hoyo, A., Barreno, E., 2011. Two Trebouxia algae with different physiological performances are ever-present in lichen thalli of Ramalina farinacea. Coexistence versus competition? Environ. Microbiol. 13, 806-818.

Cassie, D.M., Piercey-Normore, M.D., 2008. Dispersal in a sterile lichen-forming fungus, Thamnolia subuliformis (Ascomycotina: Icmadophilaceae). Botany 86, $751-762$.

Chapman, M.J., Margulis, L., 1998. Morphogenesis by symbiogenesis. Int. Microbiol. $1,319-326$.

Clement, M., Posada, D., Crandall, K.A., 2000. TCS: a computer program to estimate gene genealogies. Mol. Ecol. 9, 1657-1659.

Cordeiro, L.M.C., Reis, R.A., Cruz, L.M., Stocker-Wörgötter, E., Grube, M., Iacomini, M., 2005. Molecular studies of photobionts of selected lichens from the coastal vegetation of Brazil. FEMS Microbiol. Ecol. 54, 381-390.

Dal Grande, F., Alors, D., Divakar, P.K., Balint, M., Crespo, A., Schmitt, I., 2014. Insights into intrathalline genetic diversity of the cosmopolitan lichen symbiotic green alga Trebouxia decolorans Ahmadjian using microsatellite markers. Mol. Phylogenet. Evol. 72, 54-60.

Dal Grande, F., Widmer, I., Wagner, H.H., Scheidegger, C., 2012. Vertical and horizontal photobiont transmission within populations of a lichen symbiosis. Mol. Ecol. 21, 3159-3172.

de Bary, A., 1879. Die Erscheinung der Symbiose. Vortrag. Verlag von Karl J. Trübner Strassburg.

de Senerpont Domis, L.N., Fama, P., Bartlett, A.J., Prud'homme van Reine, W.F. Espinosa, C.A. 2003. Defining taxon boundaries in members of the morphologically and genetically plastic genus Caulerpa (Caulerpales Chlorophyta). J. Phycol. 39, 1019-1037.

del Campo, E.M., del Hoyo, A., Casano, L.M., Martínez-Alberola, F., Barreno, E., 2010a. A rapid and cost-efficient DMSO-based method for isolating DNA from cultured lichen photobionts. Taxon 59, 588-591.

del Campo, E.M., Casano, L.M., Gasulla, F., Barreno, E., 2010b. Suitability of chloroplast LSU rDNA and its diverse group I introns for species recognition and phylogenetic analyses of lichen-forming Trebouxia algae. Mol. Phylogenet. Evol. 54, 437-444.

del Campo, E.M., Catalá, S., Gimeno, J., del Hoyo, A., Martínez-Alberola, F., Casano, L. M., Grube, M., Barreno, E., 2013. The genetic structure of the cosmopolitan three-partner lichen Ramalina farinacea evidences the concerted diversification of symbionts. FEMS Microbiol. Ecol. 83, 310-323.

del Campo, E.M., del Hoyo, A., Royo, C., Casano, L.M., Álvarez, R., Barreno, E., 2010c. A single primer pair gives a specific ortholog amplicon in a wide range of Cyanobacteria and plastid-bearing organisms: applicability in inventory of reference material from collections and phylogenetic analysis. Mol. Phylogenet. Evol. 57, 1323-1328.

del Campo, E.M., Gimeno, J., De Nova, J.P.G., Casano, L.M., Gasulla, F., García-Breijo, F., Reig-Armiñana, J., Barreno, E. 2010d. South European populations of Ramalina farinacea (L.) Ach. share different Trebouxia algae. In: Nash, T.H.I. et al. (Ed.), Biology of Lichens - Symbiosis, Ecology, Environm. Monitoring, Systematics, Cyber Applications. Bibliotheca Lichenologica, J. Cranier in der Gebüder Borntraeger Verlagsbuchhandlung, Stuttgart, vol. 105, pp. 247-256.

Doering, M., Piercey-Normore, M.D., 2009. Genetically divergent algae shape an epiphytic lichen community on Jack Pine in Manitoba. Lichenologist 41, 69-80.

Drummond, A.J., Suchard, M.A., Xie, D., Rambaut, A., 2012. Bayesian phylogenetics with BEAUti and the BEAST 1.7. Mol. Biol. Evol. 29, 1969-1973.

Edgar, R.C., 2004. MUSCLE: multiple sequence alignment with high accuracy and high throughput. Nucl. Acids Res. 32, 1792-1797.

Fedrowitz, K., Kaasalainen, U., Rikkinen, J., 2012. Geographic mosaic of symbiont selectivity in a genus of epiphytic cyanolichens. Ecol. Evol. 2, 2291-2303.

Felsenstein, J., 1985. Confidence limits on phylogenies: an approach using the bootstrap. Evolution 39, 783-791.

Friedl, T., 1989. Comparative ultrastructure of pyrenoids in Trebouxid (Microthamniales, Chlorophyta). Plant Syst. Evol. 164, 145-159.

Gardes, M., Bruns, T.D., 1993. ITS primers with enhanced specificity for basidiomycetes - application to the identification of mycorrhizae and rusts. Mol. Ecol. 2, 113-118.

Geitler, L., 1926. Zur morphologie und Entwicklungsgeschichte der Pyrenoide. Arch. Protistenk 56, 128-144.

Guindon, S., Dufayard, J.F., Lefort, V., Anisimova, M., Hordijk, W., Gascuel, O., 2010. New algorithms and methods to estimate maximum-likelihood phylogenies: assessing the performance of PhyML 3.0. Syst. Biol. 59, 307-321.

Honegger, R., Zippler, U., 2007. Mating systems in representatives of Parmeliaceae, Ramalinaceae and Physciaceae (Lecanoromycetes, lichen-forming ascomycetes). Mycol. Res. 111, 424-432.

Leavitt, S.D., Kraichak, E., Nelsen, M.P., Altermann, S., Divakar, P.K., Alors, D., Esslinger, T.L., Crespo, A., Lumbsch, T., 2015. Fungal specificity and selectivity for algae play a major role in determining lichen partnerships across diverse ecogeographic regions in the lichen-forming family Parmeliaceae (Ascomycota) Mol. Ecol. 24, 3779-3797.

Leliaert, F., Verbruggen, H., Vanormelingen, P., Steen, F., López-Bautista, J.M. Zuccarello, G.C., De Clerck, O., 2014. DNA-based species delimitation in algae. Eur. J. Phycol. 49, 179-196.

Logares, R., Rengefors, K., Kremp, A., Shalchian-Tabrizi, K., Boltovskoy, A., Tengs, T. et al., 2007. Phenotypically different microalgal morphospecies with identical ribosomal DNA: a case of rapid adaptive evolution? Microb. Ecol. 53, 549-561.

Molina, M.C. Vicente, C. 1996. Ultrastructural deterioration of Xanthoria parietina (L.) Th. FR. phycobiont induced by a Xanthoria Lectin. Phyton 36 (2), 197-208.

Molins, A., Moya, P., García-Breijo, F. Reig-Armiñana, J., Barreno, E. 2015. Lichens as micro-ecosystems: novel approaches to efficiently reveal the hidden diversity of phycobionts in a single thallus. In: Munzi, S., Ulm. F. (Eds.), Eighth Int. Symb. Soc Congress. Book of Abstracts. Faculdade de Ciências, Universidade de Lisboa Portugal, p. 205. <http://iss-symbiosis.org/Resources/Documents/Abstract\% 20book.pdf>.

Moya, P., Škaloud, P., Chiva, S., García-Breijo, F.J., Reig-Armiñana, J., Vančurová, L. Barreno, E., 2015. Molecular phylogeny and ultrastructure of the lichen microalga Asterochloris mediterranea sp, nov from Mediterranean and Canary Islands ecosystems. Int. J. Syst. Evol. Microbiol. 65, 1838-1854.

Muggia, L., Grube, M., Tretiach, M., 2008. Genetic diversity and photobiont associations in selected taxa of the Tephromela atra group (Lecanorales, lichenised Ascomycota). Mycol. Prog. 7, 147-160.

Muggia, L., Zellnig, G., Rabensteiner, J., Grube, M., 2010. Morphological and phylogenetic study of algal partners associated with the lichen-forming fungus Tephromela atra from the Mediterranean region. Symbiosis 51 149-160. 
Muggia, L., Vancurova, L., Škaloud, P., Peksa, O., Wedin, M., Grube, M., 2013. The symbiotic playground of lichen thalli - a highly flexible photobiont association in rock-inhabiting lichens. FEMS Microbiol. Ecol. 85, 313-323.

Myllys, L., Lohtander, K., Tehler, A., 2001. $\beta$-tubulin, ITS and group I intron sequences challenge the species pair concept in Physcia aipolia and Physcia caesia. Mycologia 93, 335-343.

Nelsen, M.P., Gargas, A., 2008. Dissociation and horizontal transmission of codispersing lichen symbionts in the genus Lepraria (Lecanorales: Stereocaulaceae). New Phytol. 177, 264-275.

Nyati, S., Scherrer, S., Werth, S., Honegger, R., 2014. Green-algal photobiont diversity (Trebouxia spp.) in representatives of Teloschistaceae (Lecanoromycetes, lichenforming ascomycetes). Lichenologist 46, 189-212.

O'Brien, H.E., Miadlikowska, J., Lutzoni, F., 2013. Assessing population structure an host specialization in lichenized cyanobacteria. New Phytol. 198, 557-566.

Otálora, M.A., Martínez, I., O’Brien, H., Molina, M.C., Aragón, G., Lutzoni, F., 2010. Multiple origins of high reciprocal symbiotic specificity at an intercontinental spatial scale among gelatinous lichens (Collemataceae, Lecanoromycetes). Mol. Phylogenet. Evol. 56, 1089-1095.

Peksa, O, Skaloud, P., 2011. Do photobionts influence the ecology of lichens? A case study of environmental preferences in symbiotic green alga Asterochloris (Trebouxiophyceae). Mol. Ecol. 20, 3936-3948.

Piercey-Normore, M.D., 2006. The lichen-forming ascomycete Evernia mesomorph associates with multiple genotypes of Trebouxia jamesii. New Phytol. 169, 331-344.

Piercey-Normore, M., DePriest, P.T., 2001. Algal switching among lichen symbioses. Am. J. Bot. 88, 1490-1498.

Rambaut, A., 2008. FigTree: Tree Figure Drawing Tool. v1.3.1. Institute of Evolutionary Biology, University of Edinburgh.

Rambold, G., Friedl, T., Beck, A., 1998. Photobionts in lichens: possible indicators of phylogenetic relationships? Bryologist 101, 392-397.

Rikkinen, J., 1995. Chap. VIII. Patterns of dispersal and establishment in Xanthoria parietina. In: What's behind the pretty colours? A study on the photobiology of lichens. Bryobrothera. vol. 4, pp. 164-170.

Rikkinen, J., 2003. Ecological and evolutionary role of photobiont-mediated guilds in lichens. Symbiosis 34, 99-110.

Rikkinen, J., 2007. Photobiont-mediated lichen guilds. Comp. Biochem. Physiol. Part A: Mol. Integr. Physiol. 146, S219-S220.

Rikkinen, J., 2013. Molecular studies on cyanobacterial diversity in lichen symbioses. MycoKeys 6, 3-32.
Royo, C., Martínez-Alberola, F., García-Breijo, F., Gasulla, F., Reig-Armiñana, J., Salvá, G., Barreno, E., 2009. Seirophora villosa and Ramalina lacera on Junipeus turbinata share closely related Trebouxia photobionts and bacterial symbionts. XXII SLI Congress Societá Lichenologica Italiana Brescia, Italia. Not. Soc. Lich. Ital. 22, 59.

Schmull, M., Miadlikowska, J., Pelzer, M., Stocker-Worgotter, E., Hofstetter, V., Fraker, E., et al., 2011. Phylogenetic affiliations of members of the heterogeneous lichen-forming fungi of the genus Lecidea sensu Zahlbruckner (Lecanoromycetes, Ascomycota). Mycologia 103, 983-1003.

Škaloud, P., Peksa, O., 2010. Evolutionary inferences based on ITS rDNA and actin sequences reveal extensive diversity of the common lichen alga Asterochloris (Trebouxiophyceae, Chlorophyta). Mol. Phylogenet. Evol. 54, 36-46.

Škaloud, P., Steinová, J., Ridka, T., Vancurova, L., Peksa, O., 2015. Assembling the challenging puzzle of algal biodiversity: species delimitation within the genus Asterochloris (Trebouxiophyceae, Chlorophyta). J. Phycol. 51, 507-527.

Vargas Castillo, R., Beck, A., 2012. Photobiont selectivity and specificity in Caloplaca species in a fog-induced community in the Atacama Desert, northern Chile. Fungal Biol. 116, 665-676.

Werth, S., Scheidegger, C., 2012. Congruent genetic structure in the lichen-forming fungus Lobaria pulmonaria and its green-algal photobiont. Mol. Plant Microbe Interact. 25, 220-230.

Werth, S., Sork, V.L., 2010. Identity and genetic structure of the photobiont of the epiphytic lichen Ramalina menziesii on three oak species in southern California. Am. J. Bot. 97, 821-830.

White, T.J., Bruns, T., Lee, S., Taylor, J.W., 1990. Amplification and direct sequencing of fungal ribosomal RNA genes for phylogenetics. In: Innis, M.A., Gelfand, D.H., Sninsky, J.J., White, T.J. (Eds.), PCR Protocols: A Guide to Methods and Applications. Academic Press, Inc., New York, pp. 315-322.

Wiens, J.J., 2007. Species delimitation: new approaches for discovering diversity. Syst. Biol. 56, 875-878.

Wilkinson, D.M., 2001. At cross purposes. Nature 412 (6846), 485.

Wornik, S., Grube, M., 2010. Joint dispersal does not imply maintenance of partnerships in lichen symbioses. Microb. Ecol. 59, 150-157.

Yahr, R., Vilgalys, R., DePriest, P.T., 2006. Geographic variation in algal partners of Cladonia subtenuis (Cladoniaceae) highlights the dynamic nature of a lichen symbiosis. New Phytol. 171, 847-860. 